\title{
Overactivation of hepatic mechanistic target of rapamycin kinase complex 1 (mTORC1) is associated with low transcriptional activity of transcription factor EB and lysosomal dysfunction in dairy cows with clinical ketosis
}

\author{
Zhiyuan Fang, ${ }^{1 *}$ Xinwei Li, ${ }^{1 *} \oplus$ Shu Wang, ${ }^{1}$ Qianming Jiang, ${ }^{2} \odot$ Juan J. Loor, ${ }^{2} \odot$ Xiuhuan Jiang, ${ }^{1}$ Lingxue Ju, ${ }^{1}$ \\ Hao Yu, ${ }^{1}$ Taiyu Shen, ${ }^{1}$ Men Chen, ${ }^{1}$ Yuxiang Song, ${ }^{1}$ Zhe Wang, ${ }^{1}$ Xiliang Du, ${ }^{1} \dagger \odot$ and Guowen Liu ${ }^{1} \dagger \odot$ \\ ${ }^{1}$ Key Laboratory of Zoonosis, Ministry of Education, College of Veterinary Medicine, Jilin University, Changchun 130062, Jilin, China \\ ${ }^{2}$ Mammalian NutriPhysioGenomics, Department of Animal Sciences and Division of Nutritional Sciences, University of Illinois, Urbana 61801
}

\begin{abstract}
Ketosis occurs most frequently in the peripartal period and is associated with liver injury and steatosis. Lysosomes serve as the terminal degradative station and contribute to liver homeostasis through their role in the digestion of dysfunctional organelles and lipid droplets. Transcription factor EB (TFEB) has been identified as a master regulator of lysosomal function. Thus, the objective of the present study was to investigate the status of lysosomal function and TFEB transcriptional activity and potential changes in abundance of upstream effectors of TFEB identified in nonruminants, including mechanistic target of rapamycin kinase complex 1 (mTORC1), protein kinase B (Akt), glycogen synthase kinase $\beta$ (GSK3 $\beta$ ), and extracellular signal-regulated kinase1/2 (ERK1/2), and to explore which factor induces the above changes. Liver and blood samples were collected from healthy cows $(\mathrm{n}=10)$ and ketotic cows $(\mathrm{n}=10)$ that had a similar number of lactations (median $=3$, range $=2-4$ ) and days in milk (median $=6 \mathrm{~d}$, range $=3-9 \mathrm{~d})$. Calf hepatocytes were isolated from Holstein calves and treated with $10 \mathrm{ng} /$ $\mathrm{mL}$ growth hormone $(\mathrm{GH}), 3.0 \mathrm{~m} M \beta$-hydroxybutyrate (BHB), $1.5 \mathrm{ng} / \mathrm{mL}$ interleukin-18 (IL-18), $0.15 \mathrm{ng} / \mathrm{mL}$ tumor necrosis factor- $\alpha$ (TNF- $\alpha$ ), or $1.2 \mathrm{~m} M$ free fatty acid (FFA) for $12 \mathrm{~h}$. Serum levels of FFA and activities of alanine aminotransferase and aspartate aminotransferase were greater in ketotic cows, whereas glucose was lower. Additionally, ketotic dairy cows exhibited higher serum concentrations of GH, IL-18, and TNF- $\alpha$, and lower serum concentration of insulin. The lower protein abundance of lysosome-associated membrane protein 1 (LAMP1) and mRNA abundance of LAMP1 indicated
\end{abstract}

Received June 19, 2021.

Accepted January 14, 2022.

*These authors contributed equally to this work.

†Corresponding authors: duxiliang@jlu.edu.cn and liuguowen2008@ 163.com that hepatic lysosomal mass was lower in ketotic cows. Furthermore, lower protein abundance of cathepsin D (CTSD) and mRNA abundance of CTSD and V0 domain of the vacuolar ATPase along with lower activity of $\beta$ - $N$-acetylglucosaminidase indicated impairment in hepatic lysosomal function due to ketosis. The lower nuclear abundance, total protein, and mRNA abundance of TFEB and peroxisome proliferator-activated receptor $\gamma$ coactivator $1 \alpha$ along with greater phosphorylated (p)-TFEB in the liver of ketotic cows indicated an impairment of hepatic TFEB transcriptional activity. The protein abundances of phosphorylated mTOR (p-mTOR) and its downstream effectors ribosomal protein S6 kinase B (RPS6KB) and eukaryotic factor 4E-binding protein 1 (EIF4EBP1) were greater, whereas p-Akt, p-GSK3 3 , and p-ERK1/2 were lower in the liver of ketotic cows. Importantly, elevated phosphorylation of mTOR, RPS6KB, and EIF4EBP1 was observed in calf hepatocytes treated with GH, BHB, IL-18, TNF- $\alpha$, and FFA. Moreover, BHB, TNF- $\alpha$, and FFA, not GH and IL-18, reduced TFEB transcriptional activity and impaired lysosomal function in calf hepatocytes. Taken together, these data suggest that BHB, TNF- $\alpha$, and FFA overactivate the hepatic mTORC1 signaling pathway during ketosis and further impaired TFEB transcriptional activity and lysosomal function, which may contribute to liver injury and steatosis.

Key words: mechanistic target of rapamycin kinase complex 1 (mTORC1), transcription factor EB (TFEB), autophagy, liver injury, steatosis

\section{INTRODUCTION}

Ketosis, a common metabolic disorder in transition dairy cows, is characterized by high concentrations of free fatty acids (FFA) and BHB in the blood (Ospina et al., 2010; González et al., 2011). Although many peripheral tissues remove FFA from the blood (e.g., the mammary gland), up to $25 \%$ of FFA are removed by the liver (Sejersen et al., 2012). Once taken up by the 
liver, the dominant metabolic fates of FFA are (1) oxidization, either completely to $\mathrm{CO}_{2}$ or incompletely to ketone bodies (BHB, acetoacetate, and acetone); and (2) re-esterification into triacylglycerol (TG; Andersen et al., 2002). Furthermore, excessive FFA and BHB can elicit lipotoxicity and contribute to hepatic injury and steatosis (Shi et al., 2015; White, 2015; Song et al., 2016), thereby aggravating ketosis. Although liver damage and lipid accumulation have been observed in dairy cows with ketosis (Veenhuizen et al., 1991; Shen et al., 2019; Zhu et al., 2019), the precise mechanisms leading to these pathological changes are not well known.

Lysosomes, which contain more than 50 acid hydrolases specialized in breaking down damaged organelles, unfolded proteins, and lipids, are the primary cellular degradative organelles. Settembre et al. (2013) reported that hepatic abundance of lysosome-related genes, including lysosome-associated membrane protein 1 (LAMP1) and V0 domain of the vacuolar ATPase (ATP6V0A1), were lower in patients with nonalcoholic fatty liver disease. Lysosomal dysfunction aggravated chronic ethanol-induced liver injury and steatosis in mice (Chao et al., 2018b). In addition, inhibition of lysosomal function by chloroquine induced liver injury and hepatic steatosis in mice (Zhang et al., 2018a). Although severe liver injury and excessive lipid accumulation are observed in ketotic cows (Herdt, 2000; Shen et al., 2021), the status of hepatic lysosomal function is largely unexplored.

Transcription factor EB (TFEB) is a master transcription regulator of a subset of genes for lysosomal biogenesis and function, as well as genes for autophagosome formation (Martina et al., 2014; Yin et al., 2020). Activation or overexpression of TFEB upregulated abundance of hepatic lysosome-regulated genes in mice, including LAMP1 and ATP6V0A1 (Settembre et al., 2013; Fang et al., 2020). In addition, TFEB overexpression in HeLa cells promoted the abundance of autophagy genes such as microtubule-associated protein 1 light chain 3 (MAP1LC3), sequestosome-1 (SQSTM1), and autophagy-related genes (ATG12; Settembre et al., 2011). Of note, studies have reported that TFEB transcriptional activity and lysosomal function were impaired in the liver of mice and patients with nonalcoholic fatty liver disease (Settembre et al., 2013; Sinha et al., 2014). Furthermore, low mRNA abundance of MAP1LC3, SQSTM1, ATG7, and ATG12 (Shen et al., 2021) in the liver of ketotic cows suggests a decrease in autophagosome formation, implying that impaired TFEB transcriptional activity may exist in the liver of dairy cows with ketosis.

In nonruminants, mechanistic target of rapamycin kinase complex 1 (mTORC1) phosphorylates TFEB at Ser 211 to inhibit subcellular localization and transcriptional activity of TFEB (Settembre et al., 2012; Napolitano et al., 2020). Along with mTORC1, other kinases such as protein kinase B (Akt; Palmieri et

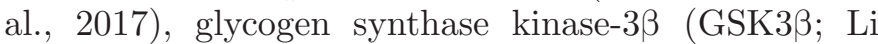
et al., 2016), and extracellular signal-regulated kinase (ERK1/2; Puertollano et al., 2018), also affect TFEB nuclear localization by phosphorylating TFEB at Ser 467, Ser 138, and Ser 211, respectively. Alterations in the activities of Akt, GSK3 $\beta$, and ERK1/2 have been reported in the livers of dairy cows with ketosis (Zachut et al., 2013; Du et al., 2017c; Shahzad et al., 2019). Thus, we hypothesized that overactivation of TFEB's upstream kinases in the liver of ketotic cows reduces TFEB transcriptional activity and impairs lysosomal function. The objectives of this study were (1) to investigate the status of lysosomal function, TFEB transcriptional activity, and activity of TFEB upstream regulators, including mTORC1, Akt, GSK3 $\beta$, and ERK1/2, in the liver of ketotic cows, and (2) to explore which factors affect the activity of mTORC1, TFEB transcriptional activity, and lysosomal function in calf hepatocytes.

\section{MATERIALS AND METHODS}

\section{Animals}

The Ethics Committee on the Use and Care of Animals at Jilin University (Changchun, China) approved the study protocol (clinical trial 202012008). Cows in the present study underwent a thorough clinical examination by the same veterinarian to ensure that cows with ketosis were free of other comorbidities. All cows were housed in a tiestall barn and offered a TMR at 0730 and $1330 \mathrm{~h}$ daily for ad libitum intake, as well as having free access to tap water. The basal diet formulation is reported in Supplemental Table S1 (https://figshare .com/articles/dataset/Over-activation_of_hepatic _mTORC1_is_associated_with_low_transcriptional _activity_of_transcription_factor_EB_and_lysosomal _dysfunction_in_dairy_cows_with_clinical_ketosis/ 18583778, Du et al., 2022). Dairy cows with similar number of lactations (median $=3$, range $=2-4$ ) and days in milk (median $=6 \mathrm{~d}$, range $=3-9 \mathrm{~d}$ ) were selected from a dairy farm located in Heihe, Heilongjiang Province, China. Cows were preliminarily classified as ketotic based on reduced feed intake and milk production, as well as a positive nitroprusside test for ketone bodies in milk (Duffield et al., 2009). Subsequently, the cows were reared separately, blood samples were collected, and blood concentrations of BHB for 3 consecutive days were determined, to ascertain the onset 
of clinical ketosis. At the same time, feed intake and milk yields were recorded during the period that blood samples were collected. According to BHB level in the blood, 10 cows whose BHB content exceeded $3 \mathrm{mM}$ were classified as clinically ketotic, and 10 cows whose BHB content was less than $1.2 \mathrm{~m} M$ were classified as healthy (Oetzel, 2004). Body weight of each cow was measured via weigh-bridge $1 \mathrm{~d}$ before liver biopsy. The BCS of each cow was assigned on the basis of a l-to5-point scale (Edmonson et al., 1989). The basic description of the cows used is reported in Supplemental Table S2 (https://figshare.com/articles/dataset/Over -activation_of_hepatic_mTORC1_is_associated_with _low_transcriptional_activity_of_transcription_factor _EB_and_lysosomal_dysfunction_in_dairy_cows _with_clinical_ketosis/18583778, Du et al., 2022).

\section{Sample Collection}

Blood samples were collected at $0700 \mathrm{~h}$ (before feeding) for 3 consecutive days from the coccygeal vein, and then the serum was separated by centrifugation at $3,500 \times g$ for $15 \mathrm{~min}$ at $4^{\circ} \mathrm{C}$. Serum was obtained and stored at $-80^{\circ} \mathrm{C}$ until analysis. During the collection of blood samples, daily milk yields were recorded at 0530 and $1500 \mathrm{~h}$ for 3 consecutive days.

Liver biopsies were collected from the 11th or 12th right intercostal space using a liver puncture needle (Shanghai Surgical Equipment Factory) once on the last day of blood sampling. The intercostal space was shaved before the liver biopsy, sanitized with iodine scrub and $75 \%$ alcohol, and anesthetized with a subcutaneous injection of $2 \%$ lidocaine $\mathrm{HCl}$ (Sigma-Aldrich Co.). A scalpel blade was used to make a $3-\mathrm{mm}$ stab incision in the skin. The puncture needle was then inserted through the intercostal muscle and into the liver. Liver tissue biopsies ( $\sim 200 \mathrm{mg})$ were immediately frozen in liquid nitrogen, and a subsample was fixed with $10 \%$ formaldehyde neutral buffer solution.

\section{Determination of Blood Parameters}

Serum concentrations of BHB, FFA, and glucose, as well as the activities of alanine aminotransferase (ALT) and aspartate aminotransferase (AST) were determined using a Hitachi 7170 autoanalyzer with commercially-available kits (BHB, cat. no. RB1008; FFA, cat. no. FA115; glucose, cat. no. GL3815; ALT, AL3801; AST, AS3804; Randox Laboratories). Assays were performed according to the manufacturers' instructions. For BHB, FFA, glucose, ALT, and AST, limits of quantification were 0.1 to $5.75 \mathrm{mM}, 0.072$ to $2.24 \mathrm{~m} M, 0.335$ to $34.1 \mathrm{~m} M, 9$ to $550 \mathrm{U} / \mathrm{L}$, and 18.7 to $670 \mathrm{U} / \mathrm{L}$, respectively.
The concentrations of growth hormone (GH), insulin, interleukin-18 (IL-18), and tumor necrosis factor- $\alpha$ $(\mathrm{TNF}-\alpha)$ in serum were measured using a bovine ELISA kit according to the manufacturer's instructions (bovine GH, P01246, Cusabio; bovine insulin, ab273188, Abcam; bovine IL-18, SEA064Bo, USCN Life Science Inc.; bovine TNF- $\alpha$, SEA133Bo, USCN Life Science Inc.). For GH, the detection range was 1.25 to $50 \mathrm{ng} / \mathrm{mL}$. Additionally, the intra- and interassay coefficients of variation for the GH assays were less than $15 \%$. For insulin, the detection range was 4.5 to $300 \mu \mathrm{IU} / \mathrm{mL}$. The intra- and interassay coefficients of variation for the insulin assays were less than $10 \%$ and $12 \%$, respectively. For TNF- $\alpha$ and IL-18, the detection ranges were 7.8 to 500 and 15.6 to $1,000 \mathrm{pg} / \mathrm{mL}$, respectively. The intraand inter-assay coefficients of variation for TNF- $\alpha$ and IL-18 were less than $10 \%$ and $12 \%$, respectively. Every sample was analyzed in triplicate, and absorbance values were read at $450 \mathrm{~nm}$ using a spectrophotometer (51119100, Thermo Fisher Scientific).

\section{Hepatocyte Isolation and Culture}

A total of 5 Holstein calves ( $1 \mathrm{~d}$ old, female, 30-40 $\mathrm{kg}$, fasting) were used in the present study. Methods for the isolation of hepatocytes were described in a previous study (Shen et al., 2021). Briefly, a scalpel was used to obtain the caudate lobe of the liver from the calf (Parker and Gaughan, 1988). Subsequently, solution A $(140 \mathrm{~m} M \mathrm{NaCl}, 10 \mathrm{~m} M$ HEPES, $6.7 \mathrm{~m} M \mathrm{KCl}, 0.5 \mathrm{~m} M$ EDTA, and $2.5 \mathrm{~m} M$ glucose; $\mathrm{pH} 7.2-7.4,37^{\circ} \mathrm{C}$ ) was used to perfuse the liver at a flow rate of $50 \mathrm{~mL} / \mathrm{min}$ for $12 \mathrm{~min}$. Then liver was perfused with solution B (140 $\mathrm{m} M \mathrm{NaCl}, 30 \mathrm{~m} M$ HEPES, $6.7 \mathrm{~m} M \mathrm{KCl}, 5 \mathrm{~m} M \mathrm{CaCl}_{2}$, and $2.5 \mathrm{~m} M$ glucose; $\mathrm{pH} 7.2-7.4,37^{\circ} \mathrm{C}$ ) at a flow rate of $50 \mathrm{~mL} / \mathrm{min}$ for $3 \mathrm{~min}$ until the outflow liquid became transparent. Subsequently, liver was digested with collagenase IV solution (cat. no. 17104019, Gibco; 68 units $/ \mathrm{mL}, \mathrm{pH} 7.2-7.4,37^{\circ} \mathrm{C}$ ) at a flow rate of $20 \mathrm{~mL} /$ $\min$ for 15 to $20 \mathrm{~min}$. The liver was moved to a sterile flat plate after digestion, and then fetal bovine serum (Hyclone Laboratories) was added to terminate collagenase digestion. Next, the liver was cut open to release hepatocytes and the liver capsule, and blood vessels and connective tissue were removed. The tissue suspension was filtered sequentially with $100-$ mesh $(150-\mu \mathrm{m})$ and 200-mesh $(75-\mu \mathrm{m})$ cell sieves. The hepatocyte suspension was washed twice in RPMI-1640 basic medium (SH30027.02, Hyclone Laboratories) and centrifuged for 5 min at $50 \times g$ at $4^{\circ} \mathrm{C}$. After isolation, hepatocytes were seeded into 6 -well tissue culture plates at $1 \times$ $10^{6}$ cells $/ \mathrm{mL}$ using adherent medium (RPMI-1640 basic medium supplemented with $10 \%$ fetal bovine serum, $10^{-6} \mathrm{~mol} / \mathrm{L}$ of insulin, $10^{-6} \mathrm{~mol} / \mathrm{L}$ of dexamethasone, 10 
$\mu \mathrm{g} / \mathrm{mL}$ of vitamin $\mathrm{C}, 100 \mathrm{U} / \mathrm{mL}$ penicillin, and $100 \mu \mathrm{g} /$ $\mathrm{mL}$ streptomycin) and incubated at $37^{\circ} \mathrm{C}$ in $5 \% \mathrm{CO}_{2}$. After $4 \mathrm{~h}$, hepatocytes began to adhere and spread, and the medium was replaced with growth medium (RPMI1640 basic medium containing 10\% fetal bovine serum and $1 \%$ penicillin/streptomycin). Cells that failed to adhere were removed during medium exchange. Growth medium was replaced every $24 \mathrm{~h}$.

\section{Reagent Preparation}

The FFA mixture was prepared according to a previous study (Du et al., 2018). Briefly, the stock fatty acid solution was prepared by diluting the fatty acid components in $0.1 \mathrm{M} \mathrm{KOH}$ at $60^{\circ} \mathrm{C}$, and the $\mathrm{pH}$ of the solution was adjusted to 7.4 with hydrochloric acid $(1 \mathrm{M})$. The stock fatty acid solution (52.7 m M; Sigma-Aldrich Co.) included oleic acid (22.9 $\mathrm{mM}$; Sigma-Aldrich Co.), linoleic acid (2.6 mM; Sigma-Aldrich Co.), palmitic acid (16.8 $\mathrm{mM}$; Sigma-Aldrich Co.), stearic acid (7.6 mM; Sigma-Aldrich Co.), and palmitoleic acid (2.8 $\mathrm{m} M$; Sigma-Aldrich Co.). The BHB (55397, Sigma-Aldrich Co.) was dissolved in distilled water and sterilized by a $0.22-\mu \mathrm{m}$ filter. The bovine IL-18 (ab117232, Abcam) and TNF- $\alpha$ (ab87904; Abcam) working solution was prepared by diluting in PBS including $0.1 \%$ BSA (V900933, Sigma-Aldrich Co.). The GH (CYT-636, ProSpec) was dissolved in ultrapure water to prepare stock solution.

\section{Hepatocyte Treatment}

The concentrations of GH, BHB, IL-18, TNF- $\alpha$, and FFA used in this study were based on the concentrations of GH (Du et al., 2018), BHB (Deng et al., 2015), IL-18 (Bao et al., 2020), TNF- $\alpha$ (Fan et al., 2021), and FFA (Rukkwamsuk et al., 2000; Zhang et al., 2020) in the blood of ketotic cows. Calf hepatocytes were maintained in RPMI-1640 basic medium containing $2 \%$ BSA and treated with $10 \mathrm{ng} / \mathrm{mL} \mathrm{GH}, 3.0 \mathrm{mM}$ BHB, $1.5 \mathrm{ng} /$ $\mathrm{mL}$ IL-18, $0.15 \mathrm{ng} / \mathrm{mL}$ TNF- $\alpha$, or $1.2 \mathrm{~m} M$ FFA for 12 h. An equivalent amount of BSA was administered to the control group.

\section{Liver Histology}

Liver tissue was fixed in $10 \%$ formaldehyde neutral buffer solution, embedded in paraffin, and cut into $8-\mu \mathrm{m}$ slices, floated on a water bath, picked up onto glass slides, and placed in slide racks. Slides were dewaxed with xylene, rehydrated through descending concentrations of alcohol, and stained with hematoxylin and eosin.

\section{TG Content Determination}

Liver tissue was homogenized with lysate provided by the Applygen Kit (E1013, Applygen Technologies Inc.). A portion of the supernatant was used to determine total protein concentration using the bicinchoninic acid assay (P1511, Applygen Technologies Inc.). The remaining supernatant was heated in a water bath $\left(70^{\circ} \mathrm{C}\right)$ for $10 \mathrm{~min}$. After cooling the samples at room temperature, they were vortexed and centrifuged at $2,000 \times g$ for $5 \mathrm{~min}$ at $4^{\circ} \mathrm{C}$. The supernatant was collected and used for a TG assay using an enzymatic kit (E1013, Applygen Technologies Inc.) following the manufacturer's instructions.

\section{$\beta-N$-Acetylglucosaminidase Assay}

The activity of $\beta$ - $N$-acetylglucosaminidase (NAG) was measured with a commercial assay kit (CS0780, Sigma-Aldrich Co.). The assay is based on the hydrolysis of the NAG substrate, 4-nitrophenyl $\mathrm{N}$-acetyl$\beta$-D-glucosaminide, by the enzyme. This enzymatic hydrolysis of the substrate releases phosphorylated nitrophenol, which, upon ionization in basic $\mathrm{pH}$, can be measured colorimetrically at $405 \mathrm{~nm}$. First, liver tissue was lysed in RIPA buffer; then $10 \mu \mathrm{g}$ from each sample was normalized to an equal volume and measured for NAG activity following the protocol provided by the supplier. Absorbance at $400 \mathrm{~nm}$ was proportional to the activity of NAG.

\section{Quantitative Real-Time PCR Analysis}

Total RNA was extracted from liver tissue using the RNAiso Plus kit (9109, TaKaRa Biotechnology Co. Ltd.) according to the manufacturer's instructions. The purity of the RNA was measured by calculating the ratio of UV activity at 260 and $280 \mathrm{~nm}$ using a Nanophotometer N50 Touch (Implen GmbH). In accordance with minimum information for publication of quantitative real-time (qRT) PCR experiments (MIQE) guidelines (Bustin et al., 2009) for assessing RNA quality, an optical density (OD) of 1.8 to 2.0 is a suitable threshold using the $\mathrm{OD}_{260}: \mathrm{OD}_{280}$ ratio. In our study, the $\mathrm{OD}_{260}$ : $\mathrm{OD}_{280}$ ratio of RNA samples ranged from 1.86 to 1.97. Gel electrophoresis (1\% agarose gels) indicated clear $18 \mathrm{~S}$ and $28 \mathrm{~S}$ bands without significant degradation, with the $28 \mathrm{~S}$ rRNA band being approximately twice as intense as the $18 \mathrm{~S}$ rRNA band. Then, the concentration of purified RNA was determined by UV spectrum at $260 \mathrm{~nm}$. Complementary (c) DNA was generated from total RNA using a reverse-transcription kit (RR047A; TaKaRa Biotechnology Co. Ltd.) according to the 
manufacturer's instructions. We evaluated mRNA expression levels using qRT-PCR technology with the SYBR Green QuantiTect RT-PCR Kit (RR420A; TaKaRa Biotechnology Co. Ltd.) and a 7500 Real-Time PCR System (Applied Biosystems Inc.). The qRT-PCR was conducted with an initial denaturation at $94^{\circ} \mathrm{C}$ for 2 min, 35 cycles of amplification (denaturation at $94^{\circ} \mathrm{C}$ for $10 \mathrm{~s}$, annealing at $62^{\circ} \mathrm{C}$ for $30 \mathrm{~s}$, and extension at $72^{\circ} \mathrm{C}$ for $45 \mathrm{~s}$ ), and extension at $72^{\circ} \mathrm{C}$ for $12 \mathrm{~min}$. The relative quantitation values were normalized to the geometric mean of the $\mathrm{C}_{\mathrm{q}}$ of the reference genes, and fold changes in mRNA abundance relative to the mean of each treatment in the control group were calculated using the $2^{-\Delta \Delta \mathrm{Ct}}$ method. The qRT-PCR reaction was performed in triplicate for each of the 10 cows per group. The relative abundance of each target gene was normalized to 2 reference genes, $\beta$-actin $(A C T B)$ and glyceraldehyde-3-phosphate dehydrogenase (GAPDH). The primer pairs used in this study were designed using Primer Express software 3.0 (Applied Biosystems Inc.) according to gene sequences published in GenBank (https://www.ncbi.nlm.nih.gov/genbank/), and are listed in Supplemental Table S3 (https://figshare .com/articles/dataset/Over-activation_of_hepatic _mTORC1_is_associated_with_low_transcriptional _activity_of_transcription_factor_EB_and_lysosomal _dysfunction_in_dairy_cows_with_clinical_ketosis/ 18583778, Du et al., 2022).

\section{Protein Extraction and Western Blotting}

Total protein was extracted using a protein extraction kit (C510003; Sangon Biotech Co. Ltd.). The cytoplasmic and nuclear proteins were prepared by using a Nuclear and Cytoplasmic Protein Extraction Kit (P0028; Beyotime Institute of Biotechnology) according to the manufacturer's instructions. Briefly, liver tissue was lysed in lysis buffer containing $10 \mathrm{~m} M$ Tris- $\mathrm{HCl}$ (pH 7.9), $140 \mathrm{mM} \mathrm{KCl,} 5 \mathrm{mM} \mathrm{MgCl}$, and $0.5 \%$ Nonidet P-40 supplemented with protease and phosphatase inhibitors (P1048; Beyotime Institute of Biotechnology). Lysed tissue was kept on ice for $15 \mathrm{~min}$. The lysates were then centrifuged at $12,000 \times g$ for 5 min at $4^{\circ} \mathrm{C}$. The supernatants (corresponding to the cytoplasmic protein) were collected. The nuclei pellets were washed 2 times with ice-cold Nonidet P-40 lysis buffer and vigorously vortexed in $0.5 \%$ Triton X-100 and $0.5 \%$ SDS in $100 \mathrm{~m} M$ Tris-HCl buffer ( $\mathrm{pH} 7.4$ ) for $30 \mathrm{~s}$ every 2 min. After vigorous shaking for $30 \mathrm{~min}$, the lysates were centrifuged at $12,000 \times g$ for $10 \mathrm{~min}$ at $4^{\circ} \mathrm{C}$. The supernatants (corresponding to the nuclear protein) were collected. The concentrations of total, cytoplasmic, and nuclear protein were determined by the bicinchoninic acid method according to the manufacturer's instructions.

Western blotting was performed as previously described (Li et al., 2020a). A total of $30 \mu \mathrm{g}$ of protein from each sample was separated on 10 to $15 \%$ Tris-glycine gels with a known prestained protein ladder (26616; Thermo Fisher Scientific). The membranes were blocked in 3\% BSA/Tris-buffered saline/ Tween (TBS-T) buffer for $4 \mathrm{~h}$ at room temperature. The blocked membranes were incubated overnight at $4^{\circ} \mathrm{C}$ with primary antibodies against mTOR $(1: 5,000$; ab2833, Abcam), phosphorylated (p)-mTOR (Ser 2448; 1:1,000; ab84400, Abcam), phosphorylated ribosomal protein S6 kinase B (p-RPS6KB; Ser 424; 1:1,000; ab131436, Abcam), RPS6KB (1:250; ab9366, Abcam), phosphorylated eukaryotic factor 4E-binding protein 1 (p-EIF4EBP1; Thr 37/46; 1:1,000; cat. no. 2855, Cell Signaling Technology), EIF4EBP1 (1:1,000; ab227540, Abcam), TFEB (1:1,000; ab2636, Abcam), p-TFEB (Ser 211; 1:1,000; cat. no. 37681, Cell Signaling Technology), LAMP1 (1:1,000; ab24170), CTSD (1:2,000; 21327-1-AP, Proteintech), Akt (1:1,000; cat. no. 9272, Cell Signaling Technology), p-Akt (Ser 473;1:1,000; cat. no. 4060, Cell Signaling Technology),

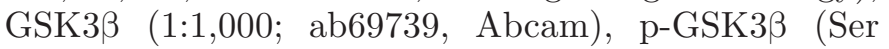
9; 1:1,000; cat. no. 9336, Cell Signaling Technology) ERK1/2 (1:1,000; cat. no. 4695, Cell Signaling Technology), p-ERK1/2 (Thr 202/Tyr 204; 1:2,000; cat. no. 4370, Cell Signaling Technology), $\beta$-tubulin (1:5,000; 10068-1-AP, Proteintech), histone H3 (1:1,000; cat. no. 4499, Cell Signaling Technology), and $\beta$-actin (1:2,000; ab8226, Abcam). Membranes were washed with TBS$\mathrm{T}$ and incubated with horseradish peroxidase-conjugated anti-rabbit or anti-mouse immunoglobulin at room temperature for $45 \mathrm{~min}$. Finally, immunoreactive bands were visualized by enhanced chemiluminescence solution (WBULS0500, Millipore). $\beta$-Actin, $\beta$-tubulin, and histone $\mathrm{H} 3$ were used as the internal controls. All bands were analyzed using Image-Pro Plus 6.0 (Media Cybernetics).

\section{Statistical Analysis}

All data were tested for normality and homoscedasticity. For a normal distribution, parametric statistical analysis was performed using independent-samples $t$ tests; for data with non-normal distribution, nonparametric statistical analysis was performed using the Wilcoxon test. All analyses were performed using GraphPad Prism 8.0 (Graph Pad Software) or SPSS 23.0 software (IBM Corp.). Data are expressed as means \pm SEM; $P$ $<0.05$ was considered statistically significant, and $P<$ 0.01 was considered extremely significant. 

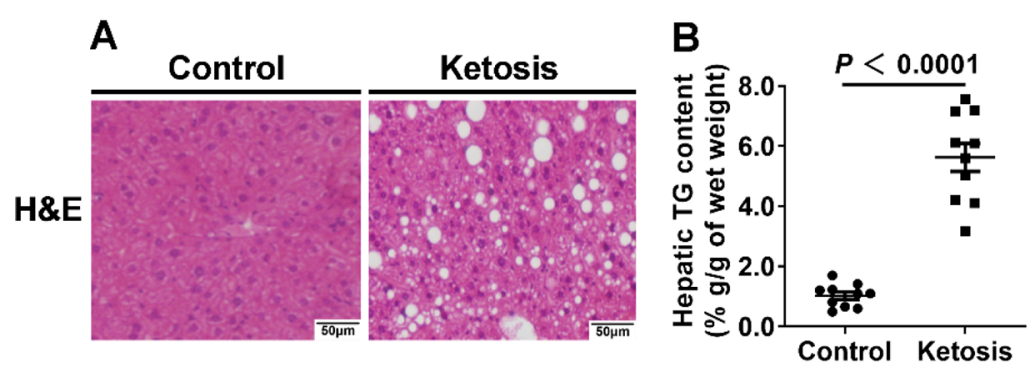

C
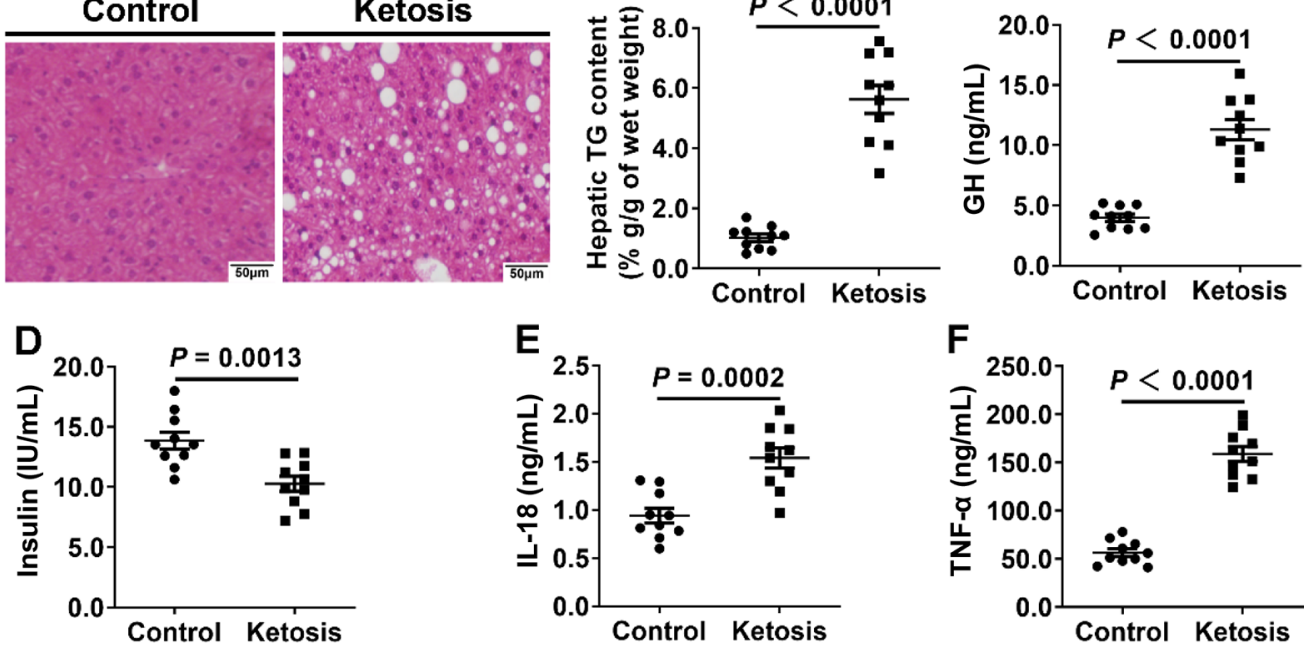

Figure 1. Liver histology and triglyceride (TG) content and serum concentrations of hormones and cytokines. (A) Representative images of hematoxylin and eosin (H\&E) staining of liver sections. Original magnification $200 \times$. Scale bar $50 \mu m$. (B) Hepatic TG content in control cows $(\mathrm{n}=10)$ and dairy cows with ketosis $(\mathrm{n}=10)$. $(\mathrm{C}-\mathrm{F})$ Serum concentrations of growth hormone $(\mathrm{GH})$, insulin, IL-18, and TNF- $\alpha$ in control cows $(\mathrm{n}=10)$ and dairy cows with ketosis $(\mathrm{n}=10)$. Data were analyzed with independent-samples $t$-tests and expressed as mean \pm SEM.

\section{RESULTS}

\section{Performance and Blood Parameters}

Milk yield and DMI of ketotic cows were lower than those of control cows (Supplemental Table S2; $P<0.01$ ), whereas BW and BCS did not differ (Supplemental Table S2). In ketotic cows, the concentrations of BHB and FFA in serum were greater (Supplemental Table S2; $P<0.01$ ), but glucose was lower (Supplemental Table S2; $P<0.01$ ). Serum activity of AST and ALT was greater in cows with ketosis (Supplemental Table S2; $P<0.01)$. Furthermore, in ketotic dairy cows, the concentrations of GH, IL-18, and TNF- $\alpha$ in the serum were greater, whereas that of insulin was lower (Figure $1 \mathrm{C}-\mathrm{F} ; P<0.01)$.

\section{Liver TG Content}

Cows with ketosis displayed hepatic lipid accumulation, as demonstrated by hematoxylin and eosin staining (Figure 1A). In addition, the content of hepatic TG in cows with ketosis was greater than in healthy cows (Figure 1B; $P<0.01$ ).

\section{Lysosomal Function in Liver}

Hepatic protein abundance of LAMP1 and mRNA abundance of $L A M P 1$, an indicator of lysosomal mass, were lower in cows with ketosis (Figure 2A, B, and D;
$P<0.01)$. Protein abundance of CTSD and mRNA abundance of CTSD and ATPase subunits ATP6V0A1 were lower in the livers of ketotic cows (Figure 2A, $\mathrm{C}, \mathrm{E}$, and F; $P<0.01)$. Hepatic activity of NAG, a lysosomal enzyme indicating the function of lysosomes, was lower in ketotic cows (Figure $2 \mathrm{G} ; P<0.01$ ).

\section{Transcriptional Activity of TFEB in Liver}

Protein levels of both cytosolic and nuclear TFEB were lower in the liver of ketotic cows compared with healthy cows (Figure 3A-C; $P<0.01$ ). Ketotic cows also exhibited a greater ratio of p-TFEB to total $(\mathbf{t})$ TFEB and a lower level of t-TFEB (Figure 3D-F; $P<$ 0.01 ). Additionally, the mRNA abundances of TFEB and peroxisome proliferator-activated receptor $\gamma$ coactivator $1 \alpha(P P A R G C 1 A)$, a direct target of TFEB (Settembre et al., 2013), were lower in the liver of ketotic cows (Figure $3 \mathrm{G}$ and $\mathrm{H} ; P<0.01$ ).

\section{Phosphorylated Status of mTORC1, Akt, GSK3 $\beta$, and ERK1/2 Signals in Liver}

Protein levels of p-mTOR and its downstream effectors, including p-RPS6KB and p-EIF4EBP1 (Figure $4 \mathrm{~A}-\mathrm{D} ; P<0.01$ ), were greater in the liver of ketotic cows compared with healthy cows. In addition, ketotic cows had lower levels of p-Akt, p-GSK3 3 , and p-ERK1/2 in the liver (Figure 4E-H; $P<0.01$ ). 
A

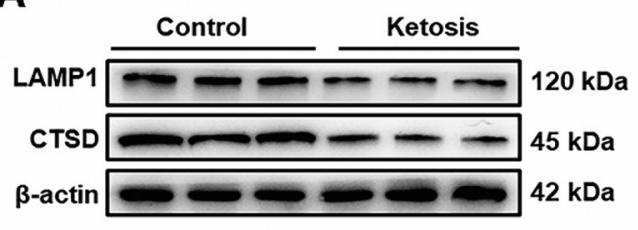

D

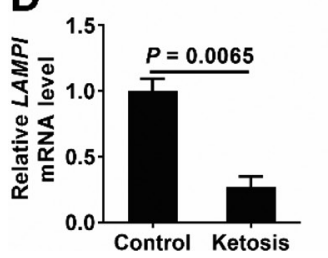

E

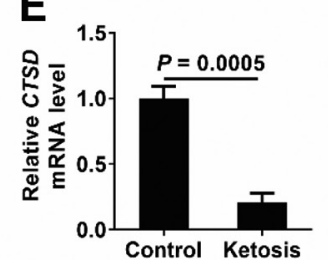

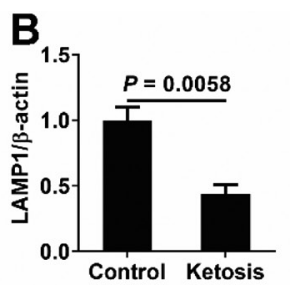

$\mathbf{F}$

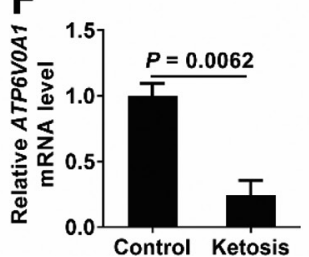

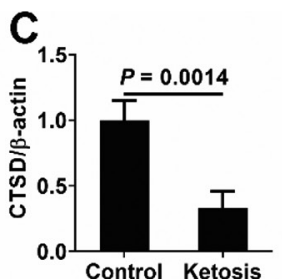

G

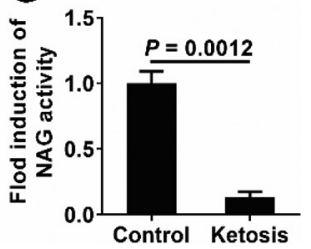

Figure 2. Hepatic status of lysosomal function. (A) Representative blots of hepatic protein levels of LAMP1 and CTSD in control cows (n $=10)$ and dairy cows with ketosis $(\mathrm{n}=10)$. (B, C) Quantification of the protein levels of LAMP1 and CTSD. (D-F) Hepatic relative mRNA abundance of LAMP1, CTSD, and V0 domain of the vacuolar ATPase $($ ATP6V0A1) in control cows $(\mathrm{n}=10)$ and dairy cows with ketosis $(\mathrm{n}=$

10). (G) Activity of $\beta$ - $N$-acetylglucosaminidase (NAG). Data were analyzed with independent-samples $t$-tests and expressed as mean \pm SEM.

\section{Effects of GH, BHB, IL-18, TNF- $\alpha$, and FFA on mTORC1 Signaling Pathway, TFEB Transcriptional Activity, and Lysosomal Function in Calf Hepatocytes}

Protein abundances of p-mTOR, p-RPS6KB, and pEIF4EBP1 were greater (Figure 5A-D; $P<0.05$ ) in calf hepatocytes treated with GH, IL-18, or TNF- $\alpha$ than control. Furthermore, BHB and FFA increased protein abundances of p-mTOR, p-RPS6KB, and p-EIF4EBP1 in calf hepatocytes (Figure 5A-D; $P<0.05$ ).

Protein levels of both cytosolic and nuclear TFEB were lower in calf hepatocytes treated with BHB, TNF- $\alpha$, and FFA compared with control (Figure 6A-C; $P<0.01)$. In addition, BHB, TNF- $\alpha$, and FFA induced a greater ratio of $\mathrm{p}$-TFEB to t-TFEB and a lower level of t-TFEB in calf hepatocytes compared with control (Figure 6D-F; $P<0.01$ ). Protein abundances
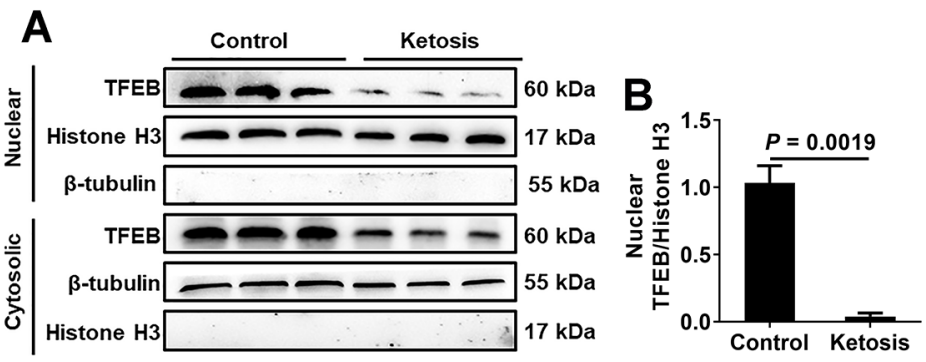

E

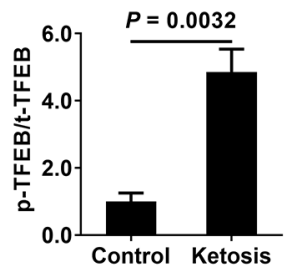

$\mathbf{F}$

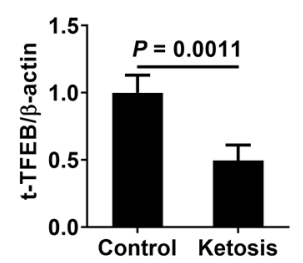

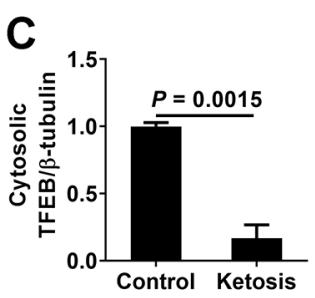

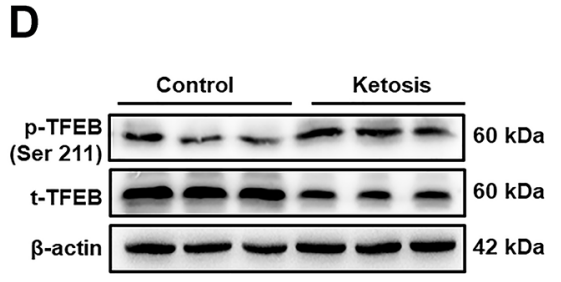

G

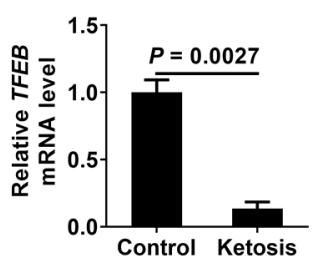

H

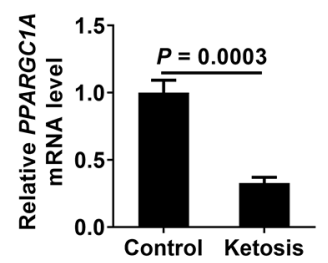

Figure 3. Hepatic transcriptional activity of TFEB. (A) Representative blots of hepatic nuclear and cytoplasmic protein levels of TFEB in control cows $(\mathrm{n}=10)$ and dairy cows with ketosis $(\mathrm{n}=10)$. $(\mathrm{B}, \mathrm{C})$ Quantification of the hepatic nuclear and cytoplasmic protein levels of TFEB. (D) Representative blots of hepatic protein levels of phosphorylated (p)-TFEB and total (t)-TFEB in control cows $(\mathrm{n}=10)$ and dairy cows with ketosis $(\mathrm{n}=10)$. (E, F) Quantification of the hepatic protein level of p-TFEB/t-TFEB and t-TFEB. (G, H) Hepatic relative mRNA abundance of TFEB and PPARGC1A in control cows $(\mathrm{n}=10)$ and dairy cows with ketosis $(\mathrm{n}=10)$. Data were analyzed with independentsamples $t$-tests and expressed as mean \pm SEM. 
of CTSD and LAMP1 were lower in calf hepatocytes treated with BHB, TNF- $\alpha$, and FFA than control (Figure $6 \mathrm{G}-\mathrm{I} ; P<0.01$ ). The mRNA abundance of TFEB, CTSD, LAMP1, and PPARGC1A were lower in calf hepatocytes treated with BHB, TNF- $\alpha$, or FFA compared with control (Figure $6 \mathrm{~K}-\mathrm{M} ; P<0.01$ ). The TFEB transcriptional activity and lysosomal function were not affect by GH and IL-18 in calf hepatocytes (Figure $6 \mathrm{~A}-\mathrm{C}$ and $\mathrm{J}-\mathrm{M} ; P<0.01$ ).

\section{DISCUSSION}

At least in nonruminants, impairment of TFEB-mediated lysosomal function is associated with liver injury and steatosis (Mészáros et al., 2018; Gilleron et al., 2019). In the present study, overactivation of mTORC1 signaling pathway and decreased TFEB transcriptional activity, as well as reduction of lysosomal function-related molecules, were accompanied by liver injury and steatosis in dairy cows with ketosis. Moreover, BHB, TNF- $\alpha$, and FFA activates mTORC1, reduces transcriptional activity of TFEB, and impairs lysosomal function in calf hepatocytes. Thus, high blood concentrations of BHB, TNF- $\alpha$, and FFA activate mTORC1 and decrease TFEB transcriptional activity, which may potentially cause lysosomal dysfunction and contribute to liver injury and steatosis and aggravate ketosis in dairy cows.

The most abundant protein component of lysosomal membranes, LAMP1 is widely used as a marker of those organelles (Terasawa et al., 2016, 2021). Thus, the lower abundance of LAMP1 is evidence that hepatic lysosomal mass was decreased during ketosis. Lysosome $\mathrm{pH}$ gradients are maintained mainly by vacuolar $\mathrm{H}^{+}$ATPases, such as ATP6V0A1 (KarsliUzunbas et al., 2014); thus, their function can alter lysosomal hydrolase activities, which work optimally at an acidic $\mathrm{pH}$. It has been reported that knockdown of ATP6V0A1 increases lysosomal $\mathrm{pH}$ and leads to a decrease in lysosomal degradative capacity (Hsin et al., 2012; Liang et al., 2020). Thus, the lower abundance of ATP6V0A1 and lower activity of NAG suggest that lysosomal function was impaired in the liver of dairy cows with ketosis. Furthermore, downregulation of the lysosomal enzymes CTSD is suggestive of lysosomal dysfunction.

Several studies have demonstrated that lysosomal activation contributed to hepatic lipid catabolism
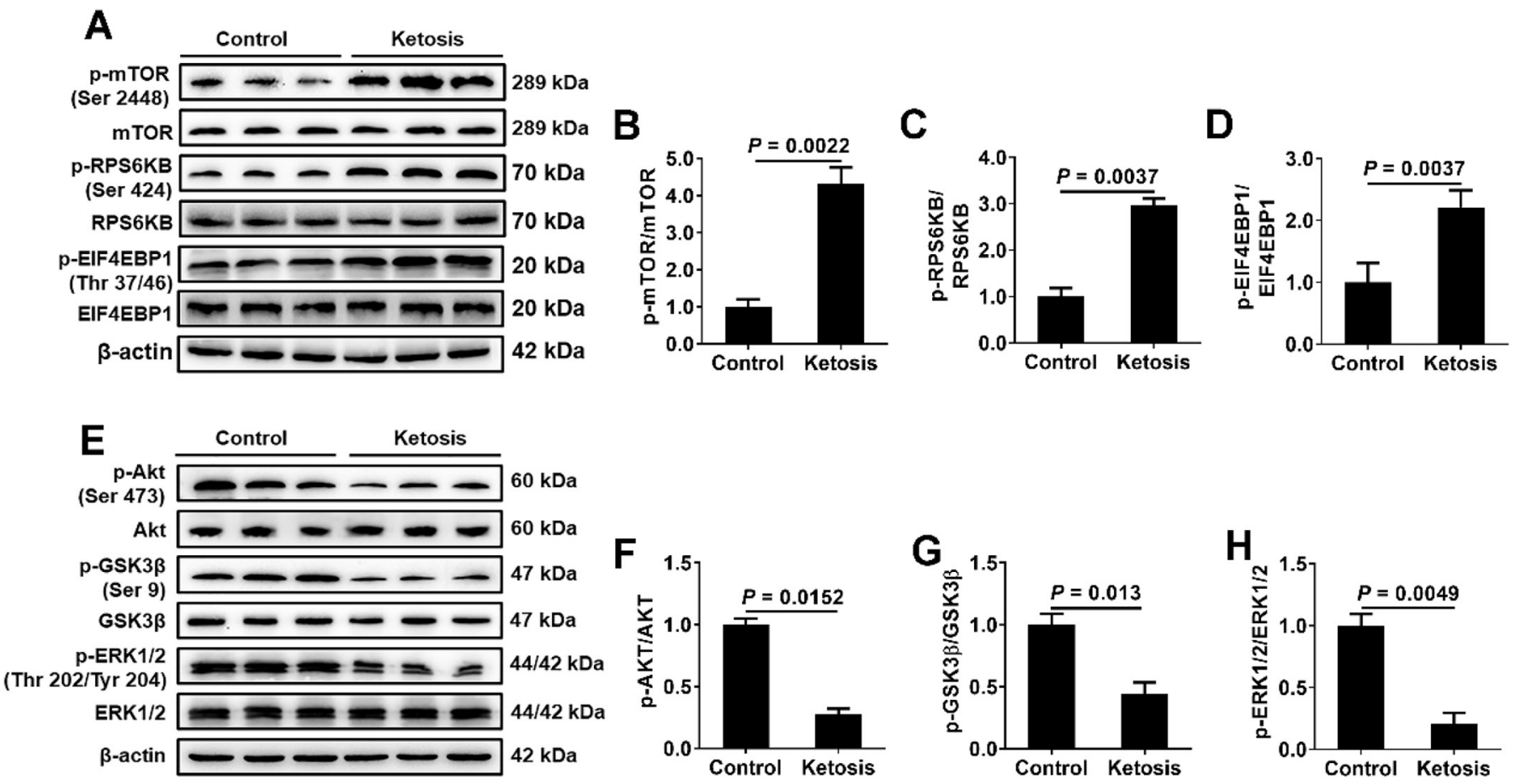

Figure 4. Phosphorylation status of mTORC1, Akt, GSK3 $\beta$, and ERK1/2 signals in the liver. (A) Representative blots of hepatic protein levels of phosphorylated (p)-mTOR, mTOR, p-RPS6KB, RPS6KB, p-EIF4EBP1, and EIF4EBP1 in control cows $(\mathrm{n}=10)$ and dairy cows with ketosis $(\mathrm{n}=10)$. (B-D) Quantification of hepatic protein levels of p-mTOR/mTOR, p-RPS6KB/RPS6KB, and p-EIF4EBP1/EIF4EBP1. (E) Representative blots of hepatic protein levels of p-Akt, Akt, p-GSK3 $\beta$, GSK3 $\beta$, p-ERK1/2, and ERK1/2 in control cows (n = 10) and dairy

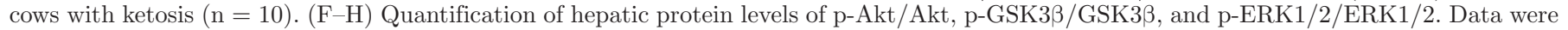
analyzed with independent-samples $t$-tests and expressed as mean \pm SEM. 
and decreased lipid accumulation in the liver of mice (Settembre et al., 2011; Wang et al., 2021). Lipid droplets can be degraded by lysosomes via macroautophagydependent mechanisms (Xu and Ren, 2015). In addition, chaperone-mediated autophagy, a lysosomal-dependent protein degradation pathway, selectively degrades lipid droplet membrane-associated proteins and facilitates recruitment of cytosolic lipases and autophagy effector proteins to the lipid droplets (Robichaud et al., 2021). Thus, hepatic steatosis observed in the present study may be partially caused by lysosomal dysfunction. Consistent with our data, inhibition of lysosomal acidification using bafilomycin $\mathrm{A} 1$, an inhibitor of vacuolar-type $\mathrm{H}^{+}$-ATPase that can prevent lysosomal degradation by neutralizing the lysosomal acidity, aggravated hepatic steatosis in mice fed a methionine- and choline-deficient diet (Zhang et al., 2017). In addition, lysosomal dysfunction caused excessive accumulation of misfolded proteins and damaged mitochondria (Nezich et al., 2015), leading to endoplasmic reticulum stress and overproduction of reactive oxygen species (FerroNovick et al., 2021; Kang et al., 2021), respectively, which partly mediate and aggravate lipid accumulation and render liver injury (Wang et al., 2015). Previous studies reported that impairment of autophagy, oxidative stress, and endoplasmic reticulum stress were driving forces behind liver injury and steatosis (Song et al., 2016; Gao et al., 2021; Shen et al., 2021). Thus, lysosomal dysfunction might be partly mediate liver injury and steatosis of ketotic cows.

The fact that ketotic dairy cows exhibited severe liver injury and impaired lysosomal function confirmed that alterations in lysosomal function contribute to liver injury. In line with these results, recent evidence
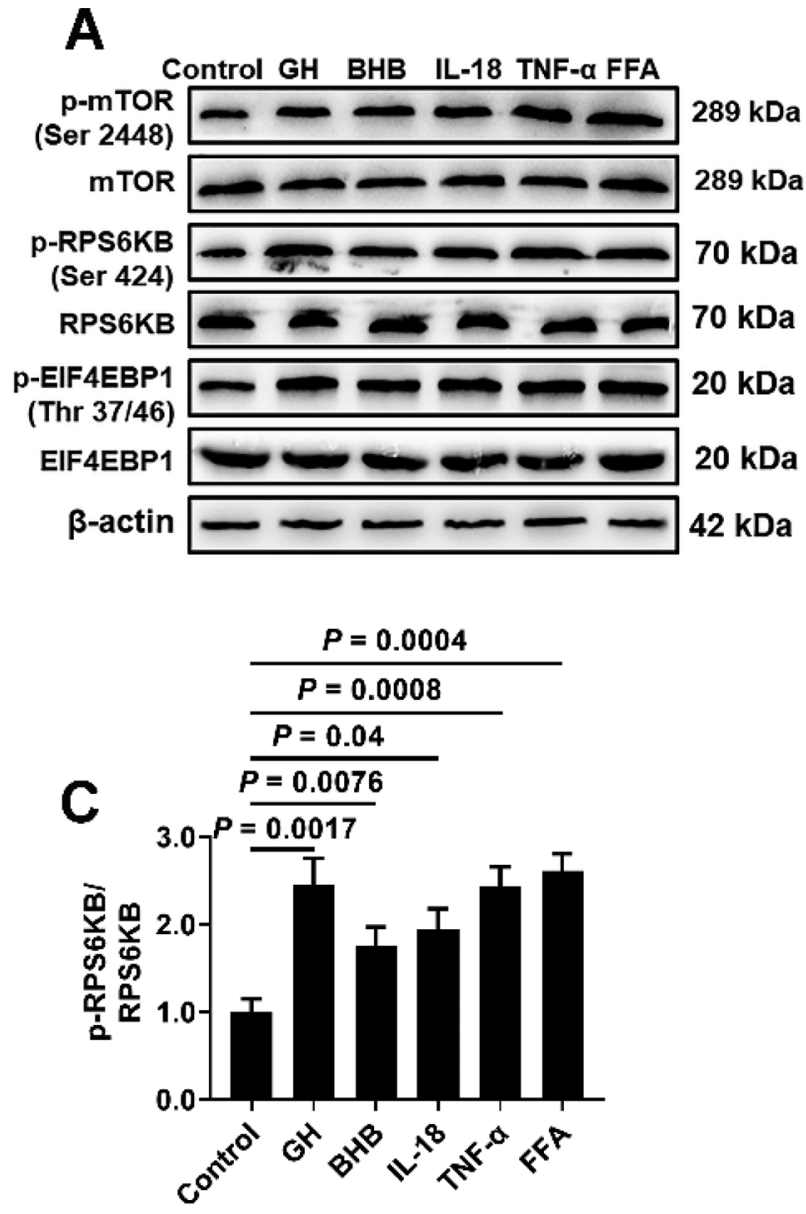
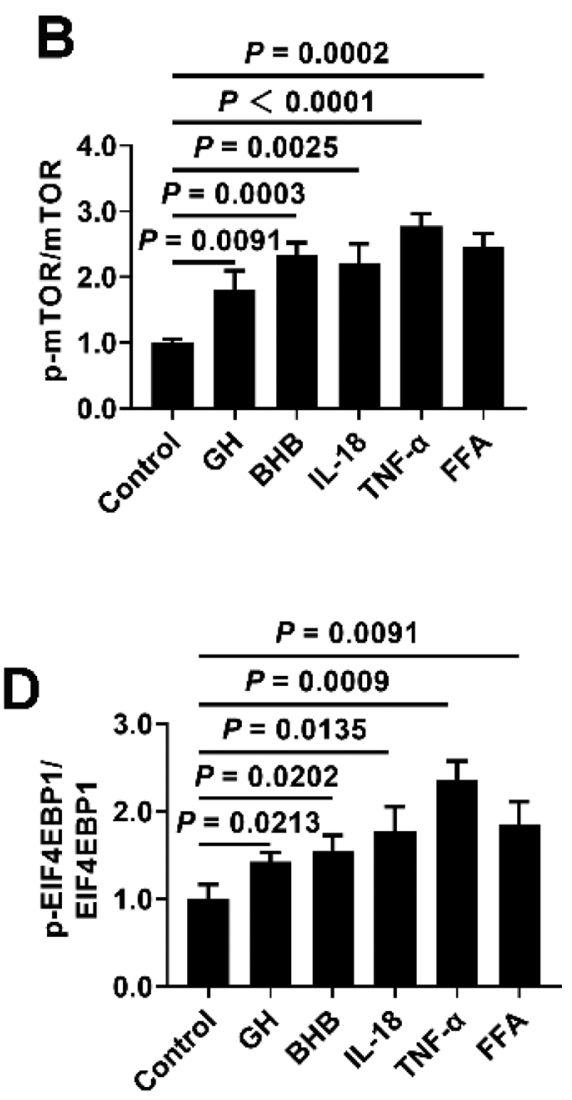

Figure 5. Effects of growth hormone (GH), BHB, IL-18, tumor necrosis factor (TNF)- $\alpha$, and free fatty acid (FFA) on the mTORC1 (mechanistic target of rapamycin kinase complex 1) signaling pathway in calf hepatocytes. Calf hepatocytes were maintained in RPMI-1640 basic medium containing $2 \%$ BSA and treated with $10 \mathrm{ng} / \mathrm{mL} \mathrm{GH,} 3.0 \mathrm{~m} M$ BHB, $1.5 \mathrm{ng} / \mathrm{mL}$ IL- $18,0.15 \mathrm{ng} / \mathrm{mL}$ TNF- $\alpha$, or $1.2 \mathrm{~m} M$ FFA for $12 \mathrm{~h}$. An equivalent amount of BSA was administered to the control group. (A) Representative blots of phosphorylated (p)-mTOR, mTOR, p-RPS6KB, RPS6KB, p-EIF4EBP1, and EIF4EBP1 in calf hepatocytes. (B-D) Quantification of protein levels of p-mTOR/mTOR, p-RPS6KB/RPS6KB, and p-EIF4EBP1/EIF4EBP1 in calf hepatocytes. Data were analyzed with independent-samples $t$-tests and expressed as mean \pm SEM. 

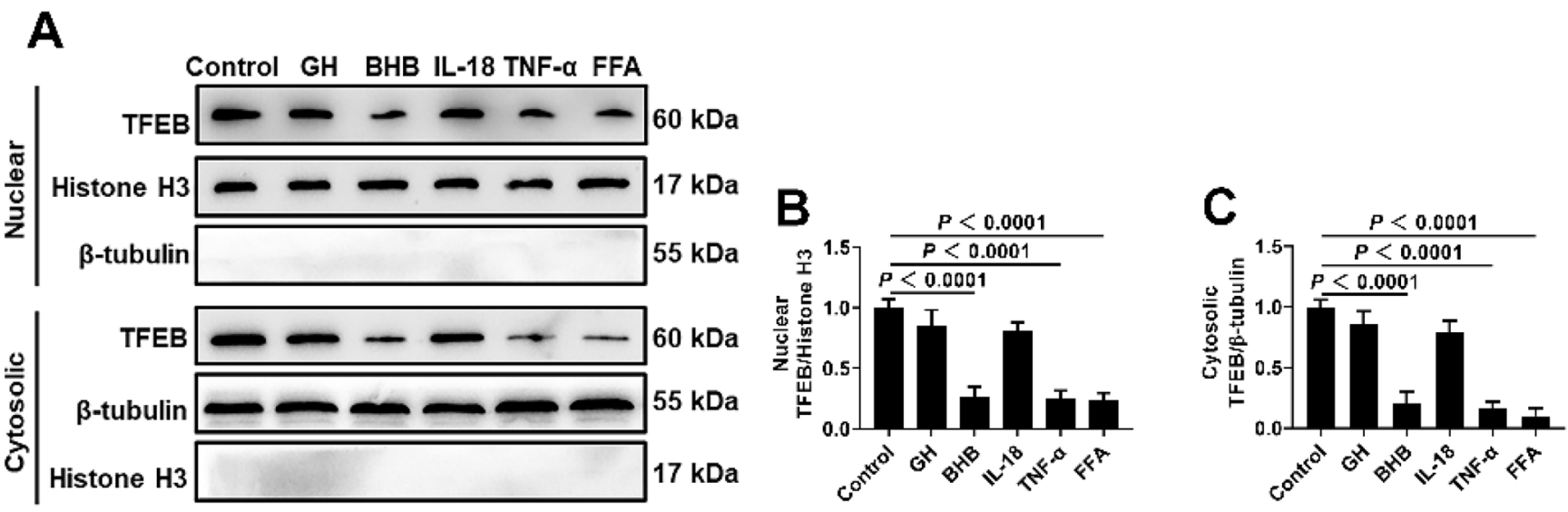

D
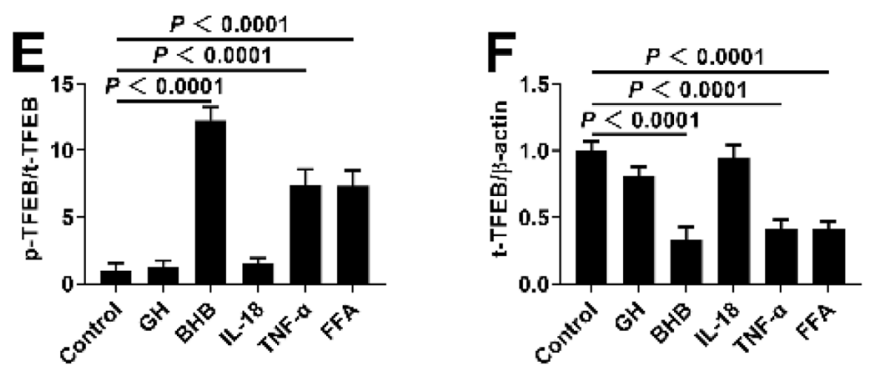

G
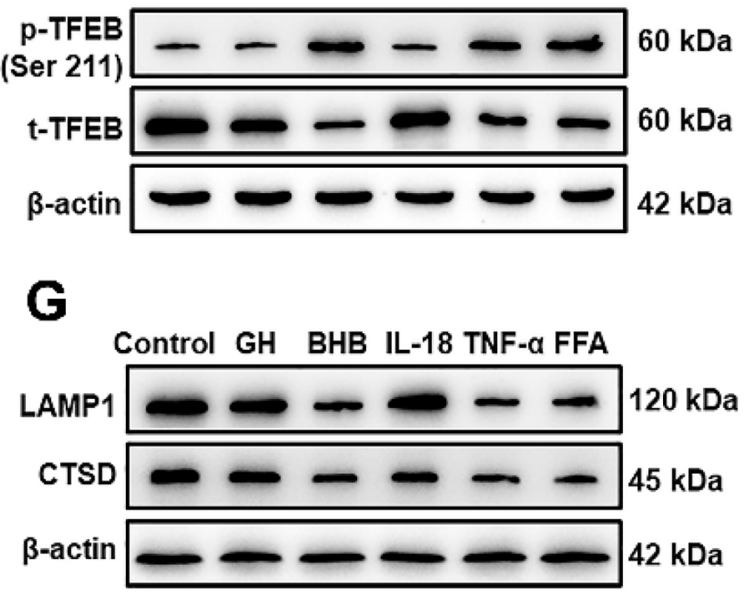

H

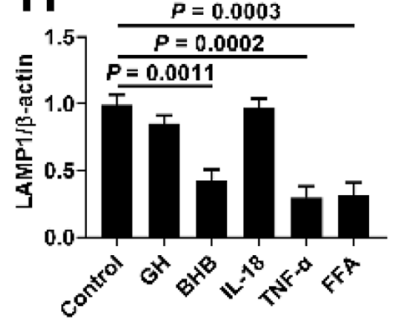

I

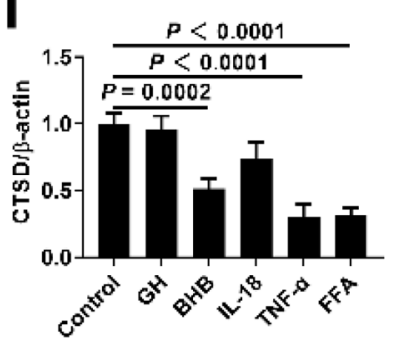

J

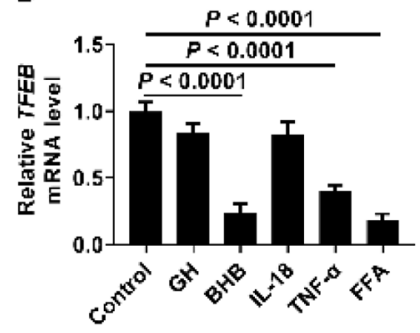

K

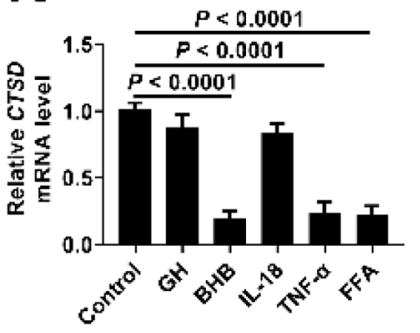

L

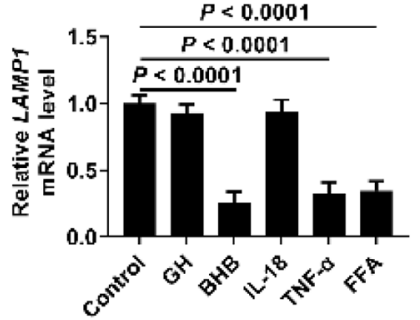

M

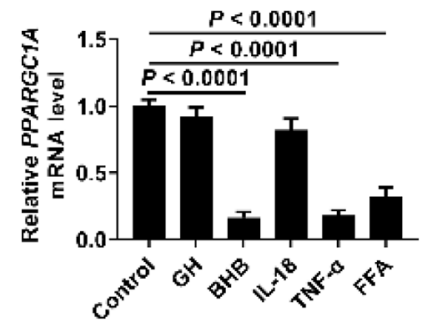

Figure 6. Effects of growth hormone (GH), BHB, IL-18, TNF- $\alpha$, and free fatty acid (FFA) on TFEB and lysosomal function in calf hepatocytes. Calf hepatocytes were maintained in RPMI-1640 basic medium containing $2 \%$ BSA and treated with $10 \mathrm{ng} / \mathrm{mL} \mathrm{GH}, 3.0 \mathrm{~m} M$ BHB $1.5 \mathrm{ng} / \mathrm{mL}$ IL-18, $0.15 \mathrm{ng} / \mathrm{mL}$ TNF- $\alpha$, or $1.2 \mathrm{mM}$ FFA for $12 \mathrm{~h}$. An equivalent amount of BSA was administered to the control group. (A) Representative blots of nuclear and cytoplasmic protein levels of TFEB in calf hepatocytes. (B, C) Quantification of the nuclear and cytoplasmic protein levels of TFEB. (D) Representative blots of protein levels of phosphorylated (p)-TFEB and total (t)-TFEB in calf hepatocytes. (E, F) Quantification of protein level of p-TFEB/t-TFEB and t-TFEB. (G) Representative blots of protein levels of LAMP1 and CTSD in calf hepatocytes. (H, I) Quantification of the protein levels of LAMP1 and CTSD. (J-M) Relative mRNA abundance of TFEB, CTSD, LAMP1, and PPARGC1A in calf hepatocytes. Data were analyzed with independent-samples $t$-tests and expressed as mean \pm SEM.

from mice indicated that liver injury and steatosis were improved by increasing lysosomal biogenesis and activities of lysosomal enzymes (Chao et al., 2018b; Lan et al., 2020; Xu et al., 2021b). Taken together, in the context of ketosis, hepatic lysosomal dysfunction may potentially contribute to liver injury and steatosis, and regulation of lysosomal function can be a therapeutic strategy for ketosis. 
The transcription factor TFEB regulates lysosomal function by inducing transcription of various genes encoding lysosomal proteins (Settembre et al., 2011; Settembre et al., 2012). Phosphorylated TFEB is sequestered into the cytoplasm, whereas dephosphorylated TFEB translocates from the cytoplasm to the nucleus, resulting in the transcription of target genes (Settembre et al., 2011). It has been reported that liverspecific TFEB knockout mice have lower numbers and activities of lysosomes (Chao et al., 2018b). However, activated TFEB can markedly increase the activities of lysosomal hydrolases, such as CTSD (Nnah et al., 2019; Choi et al., 2020). In the present study, the downregulation of TFEB abundance, nuclear localization, and lysosome-related molecules, as well as upregulated pTFEB, suggested that the transcriptional activity of TFEB was decreased.

Downregulation of TFEB target genes such as SQSTM1, ATG7, and PPARGC1A has been reported previously in the liver of ketotic cows (Gao et al., 2018; Li et al., 2020b; Shen et al., 2021). Considering the role of TFEB in regulating lysosomal function, decreased transcriptional activity of TFEB could partly explain the impairment of lysosomal function in the liver of dairy cows with ketosis. It is noteworthy that pharmacological activation of TFEB-mediated lysosomal function attenuated hepatic steatosis and liver damage in mice with fatty liver (Chao et al., 2018a; Wang et al., 2019), suggesting that targeting TFEB to prevent lysosomal dysfunction might offer opportunities to reduce liver diseases in dairy cows.

Activation of mTORC1 phosphorylation and its downstream substrates promotes anabolic while inhibiting catabolic pathways (Laplante and Sabatini, 2012; Thoreen et al., 2012). The greater phosphorylation of RPS6KB, EIF4EBP1, and TFEB in the present study are suggestive of hepatic mTORC1 overactivation during ketosis. Because hepatic overactivation of mTORC1 decreased TFEB transcriptional activity and impaired lysosomal function in mice with fatty liver (Zhang et al., 2018), it could be possible that a similar mechanism exists in dairy cows with ketosis. Thus, the reduction of lysosomal function-related molecules we detected in ketotic cows might have been associated with overactivated mTORC1 decreasing transcriptional activity of TFEB. Akt, GSK3 $\beta$, and ERK1/2 have been reported to increase the phosphorylation and decrease the nuclear translocation of TFEB (Hou et al., 2020; Frison et al., 2021). Thus, consistent with previous studies (Du et al., 2017a,b; Vieira-Neto et al., 2021), phosphorylated Akt, GSK3 $\beta$, and ERK1/2 were lower in the liver of dairy cows with ketosis, which led to the reduction in their regulation effects on TFEB transcriptional activity.
Previous studies and our results show that dairy cows with ketosis have higher blood concentrations of TNF- $\alpha$, IL-18, and GH (Song et al., 2016; El-Deeb and El-Bahr, 2017; Du et al., 2018), which could activate mTORC1 in a different way (Zhang et al., 2008; ElDarawish et al., 2018; Kimura et al., 2021). In addition, activity of AMP-activated protein kinase, one of the upstream targets of and a negative regulator of mTORC1, was decreased in calf hepatocytes treated with BHB and in mouse hepatocytes treated with FFA (Deng et al., 2016; Xu et al., 2021a). Importantly, GH, BHB, IL-18, TNF- $\alpha$, and FFA activate the mTORC1 signaling pathway in calf hepatocytes. Consistent with the activation of mTORC1, TFEB transcription activity and lysosomal function were impaired in calf hepatocytes treated with BHB, TNF- $\alpha$, and FFA. Although GH and IL-18 activated mTORC1, TFEB-mediated lysosomal function was not affected, indicating that GH and IL-18 could not regulate TFEB by mTORC1. Taken together, low hepatic TFEB transcriptional activity is associated with overactivation of hepatic mTORC1 caused by the interactions among various factors in dairy cows with clinical ketosis.

\section{CONCLUSIONS}

Growth hormone, TNF- $\alpha$, and FFA activate mTORC1, reduce transcriptional activity of TFEB, and impair lysosomal function in calf hepatocytes. Hepatic mTORC1 signaling is overactivated in dairy cows with ketosis and impairs TFEB-mediated lysosomal function. Accordingly, these changes have important implications in the context of liver injury and steatosis of dairy cows with ketosis. These findings will further improve our understanding of the pathologic mechanism of ketosis.

\section{ACKNOWLEDGMENTS}

This work was supported by the Jilin Province Science and Technology Development Project (Changchun, China; grant no. 20210508011RQ) and the National Natural Science Foundation of China (Beijing, China; grant nos. 32002349, 32022084, and 31772810). The authors have not stated any conflicts of interest.

\section{REFERENCES}

Andersen, J. B., D. G. Mashek, T. Larsen, M. O. Nielsen, and K. L. Ingvartsen. 2002. Effects of hyperinsulinaemia under euglycaemic condition on liver fat metabolism in dairy cows in early and midlactation. J. Vet. Med. A Physiol. Pathol. Clin. Med. 49:65-71. https://doi.org/10.1046/j.1439-0442.2002.jv417.x.

Bao, J., Z. Chen, L. Xu, L. Wu, and Y. Xiong. 2020. Rapamycin protects chondrocytes against IL-18-induced apoptosis and amelio- 
rates rat osteoarthritis. Aging (Albany NY) 12:5152-5167. https:/ /doi.org/10.18632/aging.102937.

Bustin, S. A., V. Benes, J. A. Garson, J. Hellemans, J. Huggett, M. Kubista, R. Mueller, T. Nolan, M. W. Pfaffl, G. L. Shipley, J. Vandesompele, and C. T. Wittwer. 2009. The MIQE guidelines: Minimum information for publication of quantitative real-time PCR experiments. Clin. Chem. 55:611-622. https://doi.org/10 .1373 /clinchem.2008.112797.

Chao, X., H. M. Ni, and W. X. Ding. 2018a. Insufficient autophagy: A novel autophagic flux scenario uncovered by impaired liver TFEBmediated lysosomal biogenesis from chronic alcohol-drinking mice. Autophagy 14:1646-1648. https://doi.org/10.1080/15548627.2018 .1489170 .

Chao, X., S. Wang, K. Zhao, Y. Li, J. A. Williams, T. Li, H. Chavan, P. Krishnamurthy, X. C. He, L. Li, A. Ballabio, H. M. Ni, and W. X. Ding. 2018b. Impaired TFEB-mediated lysosome biogenesis and autophagy promote chronic ethanol-induced liver injury and steatosis in mice. Gastroenterology 155:865-879.e12. https://doi .org/10.1053/j.gastro.2018.05.027.

Choi, S. I., J. H. Woo, and E. K. Kim. 2020. Lysosomal dysfunction of corneal fibroblasts underlies the pathogenesis of granular corneal dystrophy type 2 and can be rescued by TFEB. J. Cell. Mol. Med. 24:10343-10355. https://doi.org/10.1111/jcmm.15646.

Deng, Q., G. Liu, L. Liu, Y. Zhang, L. Yin, X. Shi, J. Wang, X. Yuan, G. Sun, Y. Li, W. Yang, L. Guo, R. Zhang, Z. Wang, X. Li, and X. Li. 2016. Effects of $\beta$-hydroxybutyric acid on the synthesis and assembly of very low-density lipoprotein in bovine hepatocytes in vitro. J. Anim. Physiol. Anim. Nutr. (Berl.) 100:331-336. https:// doi.org/10.1111/jpn.12380.

Du, X., Z. Fang, X. Li, S. Wang, Q. Jiang, and J. Loor. 2022. Over-activation of hepatic mTORC1 is associated with low transcriptional activity of transcription factor $\mathrm{EB}$ and lysosomal dysfunction in dairy cows with clinical ketosis. figshare. Dataset. https://doi.org/ 10.6084/m9.figshare.18583778.v1.

Du, X., Z. Shi, Z. Peng, C. Zhao, Y. Zhang, Z. Wang, X. Li, G. Liu, and X. Li. 2017a. Acetoacetate induces hepatocytes apoptosis by the ROS-mediated MAPKs pathway in ketotic cows. J. Cell. Physiol. 232:3296-3308. https://doi.org/10.1002/jcp.25773.

Du, X., Y. Yang, C. Xu, Z. Peng, M. Zhang, L. Lei, W. Gao, Y. Dong, Z. Shi, X. Sun, Z. Wang, X. Li, X. Li, and G. Liu. 2017b. Upregulation of miR-181a impairs hepatic glucose and lipid homeostasis. Oncotarget 8:91362-91378. https://doi.org/10.18632/oncotarget .20523

Du, X., Y. Zhu, Z. Peng, Y. Cui, Q. Zhang, Z. Shi, Y. Guan, X. Sha, T. Shen, Y. Yang, X. Li, Z. Wang, X. Li, and G. Liu. 2018. High concentrations of fatty acids and $\beta$-hydroxybutyrate impair the growth hormone-mediated hepatic JAK2-STAT5 pathway in clinically ketotic cows. J. Dairy Sci. 101:3476-3487. https://doi.org/10 $.3168 /$ jds.2017-13234

Du, X. L., L. Chen, D. Huang, Z. C. Peng, C. X. Zhao, Y. M. Zhang, Y. W. Zhu, Z. Wang, X. W. Li, and G. W. Liu. 2017c. Elevated apoptosis in the liver of dairy cows with ketosis. Cell. Physiol. Biochem. 43:568-578. https://doi.org/10.1159/000480529.

Duffield, T. F., K. D. Lissemore, B. W. McBride, and K. E. Leslie. 2009. Impact of hyperketonemia in early lactation dairy cows on health and production. J. Dairy Sci. 92:571-580. https://doi.org/ $10.3168 /$ jds.2008-1507.

Edmonson, A. J., I. J. Lean, L. D. Weaver, T. Farver, and G. Webster. 1989. A body condition scoring chart for Holstein dairy cows. J. Dairy Sci. 72:68-78. https://doi.org/10.3168/jds.S0022 -0302(89)79081-0.

El-Darawish, Y., W. Li, K. Yamanishi, M. Pencheva, N. Oka, H. Yamanishi, T. Matsuyama, Y. Tanaka, N. Minato, and H. Okamura. 2018. Frontline Science: IL-18 primes murine NK cells for proliferation by promoting protein synthesis, survival, and autophagy. J. Leukoc. Biol. 104:253-264. https://doi.org/10.1002/JLB.1HI1017 -396RR.

El-Deeb, W. M., and S. M. El-Bahr. 2017. Biomarkers of ketosis in dairy cows at postparturient period: Acute phase proteins and proinflammatory cytokines. Vet. Arh. 87:431-440. https://doi.org/10 $.24099 /$ vet.arhiv.160126c.
Fan, M., X. Du, X. Chen, H. Bai, J. J. Loor, T. Shen, Y. Liang, X. Sun, Q. Xu, Y. Song, Z. Wang, G. Liu, L. Yang, X. Li, X. Li, and W. Gao. 2021. Inhibition of cell death inducing DNA fragmentation factor- $\alpha$-like effector c (CIDEC) by tumor necrosis factor- $\alpha$ induces lipolysis and inflammation in calf adipocytes. J. Dairy Sci 104:6134-6145. https://doi.org/10.3168/jds.2020-19319.

Fang, Y., L. Ji, C. Zhu, Y. Xiao, J. Zhang, J. Lu, J. Yin, and L. Wei. 2020. Liraglutide alleviates hepatic steatosis by activating the TFEB-regulated autophagy-lysosomal pathway. Front. Cell Dev. Biol. 8:602574. https://doi.org/10.3389/fcell.2020.602574.

Ferro-Novick, S., F. Reggiori, and J. L. Brodsky. 2021. ER-phagy, ER homeostasis, and ER quality control: implications for disease. Trends Biochem. Sci. 46:630-639. https://doi.org/10.1016/j.tibs 2020.12.013.

Frison, M., D. Faccenda, R. Abeti, M. Rigon, D. Strobbe, B. S. England-Rendon, D. Cash, K. Barnes, M. Sadeghian, M. Sajic, L. A. Wells, D. Xia, P. Giunti, K. Smith, H. Mortiboys, F. E. Turkheimer, and M. Campanella. 2021. The translocator protein (TSPO) is prodromal to mitophagy loss in neurotoxicity. Mol. Psychiatry 26:2721-2739. https://doi.org/10.1038/s41380-021-01050 -z.

Gao, W., X. Du, L. Lei, H. Wang, M. Zhang, Z. Wang, X. Li, G. Liu, and X. Li. 2018. NEFA-induced ROS impaired insulin signalling through the JNK and p38MAPK pathways in non-alcoholic steatohepatitis. J. Cell. Mol. Med. 22:3408-3422. https://doi.org/10 $.1111 / \mathrm{jcmm} .13617$.

Gao, W., Z. Fang, L. Lei, L. Ju, B. Jin, J. J. Loor, Y. Liang, Z. Shi, T. Shen, H. Yu, M. Chen, H. Ouyang, Y. Song, Z. Wang, G. Liu, X. Li, and X. Du. 2021. Propionate alleviates palmitic acid-induced endoplasmic reticulum stress by enhancing autophagy in calf hepatic cells. J. Dairy Sci. 104:9316-9326. https://doi.org/10.3168/ jds.2020-19969.

Gilleron, J., J. M. Gerdes, and A. Zeigerer. 2019. Metabolic regulation through the endosomal system. Traffic 20:552-570. https:// doi.org/10.1111/tra.12670.

González, F. D., R. Muiño, V. Pereira, R. Campos, and J. L. Benedito. 2011. Relationship among blood indicators of lipomobilization and hepatic function during early lactation in high-yielding dairy cows. J. Vet. Sci. 12:251-255. https://doi.org/10.4142/jvs.2011.12.3.251.

Herdt, T. H. 2000. Ruminant adaptation to negative energy balance. Influences on the etiology of ketosis and fatty liver. Vet. Clin. North Am. Food Anim. Pract. 16:215-230. https://doi.org/10 .1016/S0749-0720(15)30102-X.

Hou, B., Y. Li, X. Li, C. Zhang, Z. Zhao, Q. Chen, N. Zhang, and H. Li. 2020. HGF protected against diabetic nephropathy via autophagy-lysosome pathway in podocyte by modulating PI3K/ Akt-GSK33-TFEB axis. Cell. Signal. 75:109744. https://doi.org/ 10.1016/j.cellsig.2020.109744.

Hsin, I. L., G. T. Sheu, M. S. Jan, H. L. Sun, T. C. Wu, L. Y. Chiu, K. H. Lue, and J. L. Ko. 2012. Inhibition of lysosome degradation on autophagosome formation and responses to GMI, an immunomodulatory protein from Ganoderma microsporum. Br. J. Pharmacol. 167:1287-1300. https://doi.org/10.1111/j.1476-5381.2012.02073.x.

Kang, S. U., D. H. Kim, Y. S. Lee, M. Huang, H. K. Byeon, S. H. Lee, S. J. Baek, and C. H. Kim. 2021. DIM-C-pPhtBu induces lysosomal dysfunction and unfolded protein response-mediated cell death via excessive mitophagy. Cancer Lett. 504:23-36. https:// doi.org/10.1016/j.canlet.2021.01.005.

Karsli-Uzunbas, G., J. Y. Guo, S. Price, X. Teng, S. V. Laddha, S. Khor, N. Y. Kalaany, T. Jacks, C. S. Chan, J. D. Rabinowitz, and E. White. 2014. Autophagy is required for glucose homeostasis and lung tumor maintenance. Cancer Discov. 4:914-927. https://doi .org/10.1158/2159-8290.CD-14-0363.

Kimura, M., K. Kurihara, H. Moteki, and M. Ogihara. 2021. Growth hormone signaling pathway leading to the induction of DNA synthesis and proliferation in primary cultured hepatocytes of adult rats. J. Pharm. Pharm. Sci. 24:1-15. https://doi.org/10.18433/ jpps31586.

Lan, W., Z. Chen, Y. Chen, M. Tan, Y. Chen, J. Chen, X. Chi, and Y. Chen. 2020. Glycochenodeoxycholic acid impairs transcription factor E3-dependent autophagy-lysosome machinery by disrupting 
reactive oxygen species homeostasis in L02 cells. Toxicol. Lett. 331:11-21. https://doi.org/10.1016/j.toxlet.2020.05.017.

Laplante, M., and D. M. Sabatini. 2012. mTOR signaling in growth control and disease. Cell 149:274-293. https://doi.org/10.1016/j .cell.2012.03.017.

Li, X., Z. Shi, Y. Zhu, T. Shen, H. Wang, G. Shui, J. J. Loor, Z. Fang, M. Chen, X. Wang, Z. Peng, Y. Song, Z. Wang, X. Du, and G. Liu. 2020a. Cyanidin-3-O-glucoside improves non-alcoholic fatty liver disease by promoting PINK1-mediated mitophagy in mice. Br. J. Pharmacol. 177:3591-3607. https://doi.org/10.1111/bph.15083.

Li, Y., M. Xu, X. Ding, C. Yan, Z. Song, L. Chen, X. Huang, X. Wang, Y. Jian, G. Tang, C. Tang, Y. Di, S. Mu, X. Liu, K. Liu, T. Li, Y. Wang, L. Miao, W. Guo, X. Hao, and C. Yang. 2016. Protein kinase C controls lysosome biogenesis independently of mTORC1. Nat. Cell Biol. 18:1065-1077. https://doi.org/10.1038/ncb3407.

Li, Y., S. Zou, H. Ding, N. Hao, Y. Huang, J. Tang, J. Cheng, S. Feng, J. Li, X. Wang, and J. Wu. 2020b. Low expression of sirtuin 1 in the dairy cows with mild fatty liver alters hepatic lipid metabolism. Animals (Basel) 10:560. https://doi.org/10.3390/ani10040560.

Liang, Y., D. Zheng, S. Peng, D. Lin, X. Jing, Z. Zeng, Y. Chen, K. Huang, Y. Xie, T. Zhou, and E. Tao. 2020. Rifampicin attenuates rotenone-treated microglia inflammation via improving lysosomal function. Toxicol. In Vitro 63:104690. https://doi.org/10.1016/j .tiv.2019.104690.

Martina, J. A., H. I. Diab, L. Lishu, L. Jeong-A, S. Patange, N. Raben, and R. Puertollano. 2014. The nutrient-responsive transcription factor TFE3 promotes autophagy, lysosomal biogenesis, and clearance of cellular debris. Sci. Signal. 7:ra9. https://doi.org/10.1126/ scisignal.2004754.

Mészáros, G., A. Pasquier, K. Vivot, A. Goginashvili, and R. Ricci. 2018. Lysosomes in nutrient signalling: A focus on pancreatic $\beta$-cells. Diabetes Obes. Metab. 20:104-115. https://doi.org/10 $.1111 /$ dom.13389.

Napolitano, G., C. Di Malta, A. Esposito, M. E. G. de Araujo, S. Pece, G. Bertalot, M. Matarese, V. Benedetti, A. Zampelli, T. Stasyk, D. Siciliano, A. Venuta, M. Cesana, C. Vilardo, E. Nusco, J. Monfregola, A. Calcagnì, P. P. Di Fiore, L. A. Huber, and A. Ballabio. 2020. A substrate-specific mTORC1 pathway underlies Birt-Hogg-Dubé syndrome. Nature 585:597-602. https://doi.org/ 10.1038/s41586-020-2444-0.

Nezich, C. L., C. Wang, A. I. Fogel, and R. J. Youle. 2015. MiT/TFE transcription factors are activated during mitophagy downstream of Parkin and Atg5. J. Cell Biol. 210:435-450. https://doi.org/10 $.1083 /$ jcb.201501002.

Nnah, I. C., B. Wang, C. Saqcena, G. F. Weber, E. M. Bonder, D. Bagley, R. De Cegli, G. Napolitano, D. L. Medina, A. Ballabio, and R. Dobrowolski. 2019. TFEB-driven endocytosis coordinates MTORC1 signaling and autophagy. Autophagy 15:151-164. https: //doi.org/10.1080/15548627.2018.1511504.

Oetzel, G. R. 2004. Monitoring and testing dairy herds for metabolic disease. Vet. Clin. North Am. Food Anim. Pract. 20:651-674. https://doi.org/10.1016/j.cvfa.2004.06.006.

Ospina, P. A., D. V. Nydam, T. Stokol, and T. R. Overton. 2010. Associations of elevated nonesterified fatty acids and $\beta$-hydroxybutyrate concentrations with early lactation reproductive performance and milk production in transition dairy cattle in the northeastern United States. J. Dairy Sci. 93:1596-1603. https://doi.org/10.3168/jds .2009-2852.

Palmieri, M., R. Pal, H. R. Nelvagal, P. Lotfi, G. R. Stinnett, M. L. Seymour, A. Chaudhury, L. Bajaj, V. V. Bondar, L. Bremner, U. Saleem, D. Y. Tse, D. Sanagasetti, S. M. Wu, J. R. Neilson, F. A. Pereira, R. G. Pautler, G. G. Rodney, J. D. Cooper, and M. Sardiello. 2017. mTORC1-independent TFEB activation via Akt inhibition promotes cellular clearance in neurodegenerative storage diseases. Nat. Commun. 8:14338. https://doi.org/10.1038/ ncomms14338.

Parker, J. E., and E. M. Gaughan. 1988. Partial hepatic resection for treatment of a single liver abscess in a dairy heifer. Vet. Surg. 17:87-89. https://doi.org/10.1111/j.1532-950X.1988.tb00283.x.

Puertollano, R., S. M. Ferguson, J. Brugarolas, and A. Ballabio. 2018. The complex relationship between TFEB transcription factor phosphorylation and subcellular localization. EMBO J. 37:e98804. https://doi.org/10.15252/embj.201798804.

Robichaud, S., G. Fairman, V. Vijithakumar, E. Mak, D. P. Cook, A. R. Pelletier, S. Huard, B. C. Vanderhyden, D. Figeys, M. LavalléeAdam, K. Baetz, and M. Ouimet. 2021. Identification of novel lipid droplet factors that regulate lipophagy and cholesterol efflux in macrophage foam cells. Autophagy 17:3671-3689. https://doi.org/ 10.1080/15548627.2021.1886839.

Rukkwamsuk, T., M. J. Geelen, T. A. Kruip, and T. Wensing. 2000. Interrelation of fatty acid composition in adipose tissue, serum, and liver of dairy cows during the development of fatty liver postpartum. J. Dairy Sci. 83:52-59. https://doi.org/10.3168/jds.S0022 $-0302(00) 74854-5$.

Sejersen, H., M. T. Sørensen, T. Larsen, E. Bendixen, and K. L. Ingvartsen. 2012. Liver protein expression in dairy cows with high liver triglycerides in early lactation. J. Dairy Sci. 95:2409-2421. https://doi.org/10.3168/jds.2011-4604.

Settembre, C., R. De Cegli, G. Mansueto, P. K. Saha, F. Vetrini, O. Visvikis, T. Huynh, A. Carissimo, D. Palmer, T. J. Klisch, A. C. Wollenberg, D. Di Bernardo, L. Chan, J. E. Irazoqui, and A. Ballabio. 2013. TFEB controls cellular lipid metabolism through a starvation-induced autoregulatory loop. Nat. Cell Biol. 15:647658. https://doi.org/10.1038/ncb2718.

Settembre, C., C. Di Malta, V. A. Polito, M. Garcia Arencibia, F. Vetrini, S. Erdin, S. U. Erdin, T. Huynh, D. Medina, P. Colella, M. Sardiello, D. C. Rubinsztein, and A. Ballabio. 2011. TFEB links autophagy to lysosomal biogenesis. Science 332:1429-1433. https:/ /doi.org/10.1126/science.1204592.

Settembre, C., R. Zoncu, D. L. Medina, F. Vetrini, S. Erdin, S. Erdin, T. Huynh, M. Ferron, G. Karsenty, M. C. Vellard, V. Facchinetti, D. M. Sabatini, and A. Ballabio. 2012. A lysosome-to-nucleus signalling mechanism senses and regulates the lysosome via mTOR and TFEB. EMBO J. 31:1095-1108. https://doi.org/10.1038/ emboj.2012.32.

Shahzad, K., V. Lopreiato, Y. Liang, E. Trevisi, J. S. Osorio, C. Xu, and J. J. Loor. 2019. Hepatic metabolomics and transcriptomics to study susceptibility to ketosis in response to prepartal nutritional management. J. Anim. Sci. Biotechnol. 10:96. https://doi.org/10 $.1186 /$ s40104-019-0404-z.

Shen, T., X. Li, J. J. Loor, Y. Zhu, X. Du, X. Wang, D. Xing, Z. Shi, Z. Fang, X. Li, and G. Liu. 2019. Hepatic nuclear factor kappa B signaling pathway and NLR family pyrin domain containing 3 inflammasome is over-activated in ketotic dairy cows. J. Dairy Sci. 102:10554-10563. https://doi.org/10.3168/jds.2019-16706.

Shen, T., F. Xu, Z. Fang, J. J. Loor, H. Ouyang, M. Chen, B. Jin, X. Wang, Z. Shi, Y. Zhu, Y. Liang, L. Ju, Y. Song, Z. Wang, X. Li, X. Du, and G. Liu. 2021. Hepatic autophagy and mitophagy status in dairy cows with subclinical and clinical ketosis. J. Dairy Sci. 104:4847-4857. https://doi.org/10.3168/jds.2020-19150.

Shi, X., D. Li, Q. Deng, Y. Li, G. Sun, X. Yuan, Y. Song, Z. Wang, X. Li, X. Li, and G. Liu. 2015. NEFAs activate the oxidative stressmediated NF- $\kappa$ B signaling pathway to induce inflammatory response in calf hepatocytes. J. Steroid Biochem. Mol. Biol. 145:103112. https://doi.org/10.1016/j.jsbmb.2014.10.014.

Sinha, R. A., B. L. Farah, B. K. Singh, M. M. Siddique, Y. Li, Y. Wu, O. R. Ilkayeva, J. Gooding, J. Ching, J. Zhou, L. Martinez, S. Xie, B. H. Bay, S. A. Summers, C. B. Newgard, and P. M. Yen. 2014. Caffeine stimulates hepatic lipid metabolism by the autophagylysosomal pathway in mice. Hepatology 59:1366-1380.

Song, Y., N. Li, J. Gu, S. Fu, Z. Peng, C. Zhao, Y. Zhang, X. Li, Z. Wang, X. Li, and G. Liu. 2016. $\beta$-Hydroxybutyrate induces bovine hepatocyte apoptosis via an ROS-p38 signaling pathway. J. Dairy Sci. 99:9184-9198. https://doi.org/10.3168/jds.2016-11219.

Terasawa, K., Y. Kato, Y. Ikami, K. Sakamoto, K. Ohtake, S. Kusano, Y. Tomabechi, M. Kukimoto-Niino, M. Shirouzu, J. L. Guan, T. Kobayashi, T. Iwata, T. Watabe, S. Yokoyama, and M. Hara-Yokoyama. 2021. Direct homophilic interaction of LAMP2A with the two-domain architecture revealed by site-directed photo-crosslinks and steric hindrances in mammalian cells. Autophagy 17:42864304. https://doi.org/10.1080/15548627.2021.1911017. 
Terasawa, K., Y. Tomabechi, M. Ikeda, H. Ehara, M. Kukimoto-Niino, M. Wakiyama, K. A. Podyma-Inoue, A. R. Rajapakshe, T. Watabe, M. Shirouzu, and M. Hara-Yokoyama. 2016. Lysosomeassociated membrane proteins-1 and -2 (LAMP-1 and LAMP-2) assemble via distinct modes. Biochem. Biophys. Res. Commun. 479:489-495. https://doi.org/10.1016/j.bbrc.2016.09.093.

Thoreen, C. C., L. Chantranupong, H. R. Keys, T. Wang, N. S. Gray, and D. M. Sabatini. 2012. A unifying model for mTORC1-mediated regulation of mRNA translation. Nature 485:109-113. https:// doi.org/10.1038/nature11083.

Veenhuizen, J. J., J. K. Drackley, M. J. Richard, T. P. Sanderson, L. D. Miller, and J. W. Young. 1991. Metabolic changes in blood and liver during development and early treatment of experimental fatty liver and ketosis in cows. J. Dairy Sci. 74:4238-4253. https:/ /doi.org/10.3168/jds.S0022-0302(91)78619-0.

Vieira-Neto, A., R. Zimpel, F. R. Lopes Jr., T. L. Scheffler, E. Block, W. W. Thatcher, and J. E. P. Santos. 2021. Duration and degree of diet-induced metabolic acidosis prepartum alter tissue responses to insulin in dairy cows. J. Dairy Sci. 104:1660-1679. https://doi .org/10.3168/jds.2020-18787.

Wang, J., P. Yu, X. Xie, L. Wu, M. Zhou, F. Huan, L. Jiang, and R. Gao. 2021. Bisphenol $\mathrm{F}$ induces nonalcoholic fatty liver diseaselike changes: Involvement of lysosome disorder in lipid droplet deposition. Environ. Pollut. 271:116304. https://doi.org/10.1016/ j.envpol.2020.116304

Wang, L., X. Liu, J. Nie, J. Zhang, S. R. Kimball, H. Zhang, W. J. Zhang, L. S. Jefferson, Z. Cheng, Q. Ji, and Y. Shi. 2015. ALCAT1 controls mitochondrial etiology of fatty liver diseases, linking defective mitophagy to steatosis. Hepatology 61:486-496. https://doi .org/10.1002/hep.27420.

Wang, Y., H. Zhao, X. Li, Q. Wang, M. Yan, H. Zhang, T. Zhao, N. Zhang, P. Zhang, L. Peng, and P. Li. 2019. Formononetin alleviates hepatic steatosis by facilitating TFEB-mediated lysosome biogenesis and lipophagy. J. Nutr. Biochem. 73:108214. https:// doi.org/10.1016/j.jnutbio.2019.07.005.

White, H. M. 2015. The role of TCA cycle anaplerosis in ketosis and fatty liver in periparturient dairy cows. Animals (Basel) 5:793-802. https://doi.org/10.3390/ani5030384.

Xu, H. X., and D. J. Ren. 2015. Lysosomal physiology. Annu. Rev. Physiol. 77:57-80. https://doi.org/10.1146/annurev-physiol -021014-071649.

Xu, N., H. Luo, M. Li, J. Wu, X. Wu, L. Chen, Y. Gan, F. Guan, M. Li, Z. Su, J. Chen, and Y. Liu. 2021a. $\beta$-Patchoulene improves lipid metabolism to alleviate non-alcoholic fatty liver disease via activating AMPK signaling pathway. Biomed. Pharmacother. 134:111104. https://doi.org/10.1016/j.biopha.2020.111104.

Xu, Y., H. Ke, Y. Li, L. Xie, H. Su, J. Xie, J. Mo, and W. Chen. 2021b. Malvidin-3-O-glucoside from blueberry ameliorates nonal- coholic fatty liver disease by regulating transcription factor ebmediated lysosomal function and activating the nrf2/are signaling pathway. J. Agric. Food Chem. 69:4663-4673. https://doi.org/10 1021/acs.jafc.0c06695

Yin, Q., Y. Jian, M. Xu, X. Huang, N. Wang, Z. Liu, Q. Li, J. Li, H. Zhou, L. Xu, Y. Wang, and C. Yang. 2020. CDK4/6 regulate lysosome biogenesis through TFEB/TFE3. J. Cell Biol. 219:e201911036. https://doi.org/10.1083/jcb.201911036.

Zachut, M., H. Honig, S. Striem, Y. Zick, S. Boura-Halfon, and U. Moallem. 2013. Periparturient dairy cows do not exhibit hepatic insulin resistance, yet adipose-specific insulin resistance occurs in cows prone to high weight loss. J. Dairy Sci. 96:5656-5669. https: //doi.org/10.3168/jds.2012-6142.

Zhang, B., M. Li, W. Yang, J. J. Loor, Y. Liang, S. Wang, Y. Zhao, H. Guo, X. Ma, L. Yu, and C. Xu. 2020. Mitochondrial dysfunction and endoplasmic reticulum stress in calf hepatocytes are associated with fatty acid-induced ORAI calcium release-activated calcium modulator 1 signaling. J. Dairy Sci. 103:11945-11956. https: //doi.org/10.3168/jds.2020-18684.

Zhang, H., S. Yan, B. Khambu, F. Ma, Y. Li, X. Chen, J. A. Martina, R. Puertollano, Y. Li, N. Chalasani, and X. M. Yin. 2018. Dynamic MTORC1-TFEB feedback signaling regulates hepatic autophagy, steatosis and liver injury in long-term nutrient oversupply. Autophagy 14:1779-1795. https://doi.org/10.1080/15548627 .2018.1490850.

Zhang, J., Z. Gao, J. Yin, M. J. Quon, and J. Ye. 2008. S6K directly phosphorylates IRS-1 on Ser-270 to promote insulin resistance in response to TNF- $\alpha$ signaling through IKK2. J. Biol. Chem. 283:35375-35382. https://doi.org/10.1074/jbc.M806480200.

Zhang, X., W. K. Wu, W. Xu, K. Man, X. Wang, J. Han, W. Y. Leung, R. Wu, K. Liu, and J. Yu. 2017. C-X-C motif chemokine 10 impairs autophagy and autolysosome formation in non-alcoholic steatohepatitis. Theranostics 7:2822-2836. https://doi.org/ 10.7150/thno. 19068 .

Zhu, Y., G. Liu, X. Du, Z. Shi, M. Jin, X. Sha, X. Li, Z. Wang, and X. Li. 2019. Expression patterns of hepatic genes involved in lipid metabolism in cows with subclinical or clinical ketosis. J. Dairy Sci. 102:1725-1735. https://doi.org/10.3168/jds.2018-14965.

\section{ORCIDS}

Xinwei Li ๑ https://orcid.org/0000-0002-0765-677X

Qianming Jiang ( ) https://orcid.org/0000-0001-9522-4856

Juan J. Loor @ https://orcid.org/0000-0003-1586-4365

Xiliang Du ( ) https://orcid.org/0000-0002-1467-6998

Guowen Liu $\odot$ https://orcid.org/0000-0002-2672-6104 